\title{
Phylogenetic systematics of Archembiidae (Embiidina, Insecta)
}

\author{
CLAUDIA A. SZUMIK
}

CONICET - Instituto Superior de Entomologia 'Dr Abraham Willink', Miguel Lillo 205, C.P. 4000, San Miguel de Tucuman, Tucuman, Argentina

\begin{abstract}
A cladistic analysis of the American genera of Embiidae is presented, using fifty-seven representative taxa and ninety-four morphological characters. The results support the elevation (and significant re-delimitation) of the subfamily Archembiinae to family level; as delimited here, Archembiidae, revised status, includes the genera Ecuadembia n.gen., Calamoclostes Enderlein, Archembia Ross, Embolyntha Davis, Xiphosembia Ross, Ochrembia Ross, Dolonembia Ross, Conicercembia Ross, Neorhagadochir Ross, Pachylembia Ross, Rhagadochir Enderlein, Litosembia Ross, Navasiella Davis, Ambonembia Ross, Malacosembia Ross, Biguembia Szumik, Gibocercus Szumik and Pararhagadochir Davis. The results also indicate that some genera recently proposed are unjustified and therefore they are synonymized: Argocercembia Ross (a junior synonym of Embolyntha), Brachypterembia Ross (Neorhagadochir), Scelembia Ross (Rhagadochir), Ischnosembia Ross (Ambonembia) and Aphanembia Ross (Biguembia); all new synonymy. The new genus Ecuadembia is described (type species Archembia arida Ross). Ischnosembia surinamensis (Ross) is returned to the genus Pararhagadochir. The following species synonymies are established: Archembia lacombea Ross 1971 = Archembia kotzbaueri (Navas 1925), Archembia peruviana Ross 2001=Archembia batesi (MacLachlan 1877), and Conicercembia septentrionalis (Mariño \& Márquez 1988) = Conicercembia tepicensis Ross 1984; all new synonymy. The family Archembiidae, and all its constituent genera, are diagnosed and described. The genus Microembia Ross (originally described as an Embiidae) is transferred to Anisembiidae. Pachylembiinae, Scelembiinae, and Microembiinae proposed by Ross are unsupported by the present cladistic analysis. ${ }^{1}$
\end{abstract}

Correspondence: Claudia A. Szumik, CONICET - Instituto Superior de Entomologia 'Dr Abraham Willink', Miguel Lillo 205, C.P. 4000, San Miguel de Tucuman, Tucuman, Argentina. E-mail: instlillo@infovia.com.ar

\footnotetext{
${ }^{1}$ Note from the editors: We are aware that several taxa reviewed in this manuscript have not been examined by the author, and proposed synonymy and character states scored for the matrix have been derived from publication(s) alone. Although this is unsound taxonomic practice, we accept that in this case it is unavoidable. The specimens, which reside in the Embiidina collection curated by Ross at the California Academy of Sciences, over more than a decade have not been made available for loan to the author (requests and refusal correspondence viewed by P. S. Cranston). Furthermore, type specimens purportedly deposited in the Smithsonian Institution and Natural History Museum (London) had not been received there by mid-2003 (letters to editor Cranston, 2003).

According to Recommendation 72F.3 ('Institutional responsibility') of the International Code for Zoological Nomenclature, 'Every institution in which name-bearing types are deposited should ... make them accessible for study'. We are aware of the problems managers and curators of collections may have with individual recalcitrant researchers, but feel that this footnote is a necessary explanation for aspects of this manuscript that may seem deficient.
} 


\section{Introduction}

Embiidae, with forty-two genera and 150 described species, contains almost half the known species of the order Embiidina and is the only family present on more than one continent (four) and in more than one biogeographical region (four). Historically, Embiidae has been defined by the possession of a bladder in the hind basitarsus, the medial vein of the anterior wing being furcate, and the apical process of the left cercus setose. All these features, however, are either convergences, or define a larger group of Embiidina. The very wide distribution and numerous species in the family therefore reflect more artefact than reality. Davis (1938, $1940 \mathrm{c}, \mathrm{d})$ had already noted the lack of naturalness in the family, considering Embiidae as polyphyletic; Szumik (1996) corroborated Davis' ideas in a phylogenetic analysis of the order. In that study (Szumik, 1996), even the American genera of Embiidae appeared as a nonmonophyletic group, although they do possess some characters which might indicate monophyly. Thus, in a subsequent analysis (Szumik, 1998b) including a larger number of representatives, the American genera grouped with the African genera Scelembia Ross, Rhagadochir Enderlein and Navasiella Davis, in a relationship stable to the subsequent addition of more taxa and characters (Szumik, 2000a,b). The placement of Microembia (originally described as Embiidae) was also stable, as sister group of Chelicerca Ross (Anisembiidae).

The studies by Szumik (1996, 1998b) represented only a first approximation to the problem. The other recent contribution to the American Embiidae is that of Ross (2001), who concentrated only on the alpha-level taxonomy of the group. Ross (2001) added nine new genera (seven of which were monotypic) to the ten American genera previously described for Embiidae, and divided the American Embiidae into four subfamilies, Archembiinae, Microembiinae (monotypic), Scelembiinae and Pachylembiinae (monotypic). However, the results of Szumik (1996, 1998b) suggest that some of the subfamilies or genera Ross recognized may not be monophyletic; in some cases taxa erected by Ross simply reflect the tradition of erecting new groups for highly autapomorphic or plesiomorphic conditions of pre-existing taxa.

Given this situation, evidently a phylogenetic analysis of the American Embiidae including all characters relevant to the group is desirable. Few of these characters are discussed by Ross (2001) who focused more on the species-level treatment, and therefore concentrated on putative species-level characters (coloration, male terminalia). Thus, using previous studies of the order as a framework, a more complete cladistic analysis of the Embiidae is undertaken here, including outgroup taxa appropriate to test monophyly. On the basis of the cladistic analysis presented here, the subfamily Archembiinae is elevated to familial status and includes all American Embiidae (with the exception of Microembia), plus the African genera Rhagadochir (=Scelembia) and Navasiella. Cladistic analyses show that the subfamilies Scelembiinae and Pachylembiinae proposed by Ross (2001), as well as certain genera, are delimited incorrectly. The Peruvian genus Microembia is transferred to Anisembiidae.

\section{Materials and methods}

The material used in this study was generously lent by the following people and institutions: Randall T. Schuh, The American Museum of Natural History, New York, U.S.A. (AMNH); John E. Rawlins, The Carnegie Museum of Natural History, Pittsburgh, U.S.A. (CMNH); Enrique Mariño, Instituto de Biología, Universidad Autónoma de México, Mexico (IBUNAM); Axel O. Bachmann, Museo Argentino de Ciencias Naturales, Buenos Aires, Argentina (MACN); Stephan P. Cover, Museum of Comparative Zoology, Massachusetts, U.S.A. (MCZ); Jean Legrand, Muséum National d'Histoire Naturelle, Paris, France (MNHN); Adriano Kury, Museo Nacional de Rio de Janeiro, Rio de Janeiro, Brazil (MNRJ); Eliane De Coninck, Musée Royal de l'Afrique Centrale, Tervuren, Belgium (MRAC); Alcide Costa, Museu de Zoologia, São Paulo, Brazil (MZSP); Arno A. Lise, Pontificia Universidade Católica do Rio Grande do Sul, Porto Alegre, Brazil (PUC-RS); David A. Nickle, United States National Museum of Natural History, Washington, U.S.A. (USNM); Jürgen Deckert, Museum für Naturkunde, Humbold Universität, Berlin, Germany (ZMB). The material collected by the author is deposited in the Instituto and Fundación Miguel Lillo, Tucumán, Argentina (IFML).

The following abbreviations have been used: Mm, mentum; Sm, submentum; wing base union (Szumik, 1996): type $\mathrm{A}, \mathrm{Rs}+\mathrm{Ma}$ and $\mathrm{Mp}$ fork together from $\mathrm{Cu}$, a broader cross-vein present between $\mathrm{Rs}+\mathrm{Ma}$ and $\mathrm{R}_{1}$; type $\mathrm{B}$, $\mathrm{Rs}+\mathrm{Ma}$ and Mp start separately from a cross-vein between $\mathrm{R}_{1}$ and $\mathrm{Cu}$; type $\mathrm{C}, \mathrm{Rs}+\mathrm{Ma}$ and $\mathrm{Mp}$ start fused from a cross-vein between $\mathrm{R}_{1}$ and $\mathrm{Cu} ; 1^{\circ} \mathrm{Vfs}$, rudiments of valvifers one; Ep, epiproct; Lpp, left paraproct; Rpp, right paraproct; $\mathrm{H}$, hypandrium or ninth sternite; $\mathrm{Hp}$, process of the hypandrium; LC1, basal left cercus; LC1dp, distal process of $\mathrm{LC} 1$; LC1bp, basal process of $\mathrm{LC} 1$; LC2, apical left cercus; $10 \mathrm{~T}$, tenth tergite; $10 \mathrm{~L}$, tenth left hemitergite; 10R, tenth right hemitergite; 10Lp1, caudal process of the left hemitergite; 10Rp1, caudal process of the right hemitergite; 10Rp2, anterior process of the right hemitergite.

\section{Cladistic analysis}

The choice of trees was made using the implied weighting method of Goloboff (1993a), implemented in the program PEE-wEE version 2.9 (Goloboff, 1993b). The search algorithm used for the data matrix with ninety-four morphological characters and fifty-seven taxa (Appendix 1) was the 'parsimony ratchet' of Nixon (1999), with thirty replications of a random addition sequence, each followed by fifty iterations of tree bisection-reconnection (TBR)-ratchet (thus totalling 1500 ratchet iterations). The group support was measured with a jackknifing procedure modified from Farris et al. (1996), where in each replication (500 in total) a more exhaustive search is done (three random addition sequences, each followed by TBR, saving up to 500 trees). The support for each group was measured as the GC value, which is the 
difference in frequency for the group, and the most frequent contradictory group (Horovitz, 1999; Goloboff et al., 2003).

\section{Taxa}

Ten taxa of the families Clothodidae and Embiidae were selected as outgroups (see Appendix 2); as long acknowledged (and supported and discussed in Szumik, 1996, 1998b, 2002), the genera of Clothodidae form the most basal branches of the order. The analysis included all the American genera of Archembiidae, with the exception of Microembia (transferred to Anisembiidae) and six of the seven species in the African genera Rhagadochir (= Scelembia) and Navasiella. Of the fiftyseven species included in the analysis, fifteen were scored on the basis of the original descriptions, as material was not available; the remaining forty-two (see Appendix 2) were scored on the basis of type and common specimens with the exception of eight taxa. For the choice of included taxa, many more species were studied, but they represented no significantly different character combinations, and would thus have added minimally to the analysis.

\section{Characters}

Ninety-four morphological characters were used; only brief comments are included here; a more detailed description of the characters and states is provided in Appendix 3.

Coloration ( six characters, both sexes). Colour characters have sometimes been used to recognize genera of Embiidina (e.g. Ross, 1960 distinguished Scelembia from Rhagadochir only on the basis of colour differences; Ross, 2001 continues explicitly to defend the use of coloration). I have observed colour characters (such as the degree of pigmentation) to vary in specimens of the same nest, in different seasons, and with the time elapsed since the last moult; this casts doubt on the use of such characters for higher groups. Although these characters are doubtful, it seemed better to include them in the analysis, so that their reliability could be checked against the distribution of other characters.

The three basic colour conditions recorded here have been observed to vary independently in males and females; thus, the male and female characters are considered as independent.

Head (seven characters, males). The head characters most often used in systematics concern the male mandibles. Other informative male characters have been found in the mouthparts and cephalic capsule. The shape of the mentum and submentum is easy to observe (Figs 1-5) and the presence of no less than seventeen possible states in the order makes their utilization potentially useful. However, homologizing all the possible conditions in the shape of the mentum and submentum is a difficult task; only the most relevant differences were used here.

Hind basitarsus ( six characters, males and females). This article seems to be used as anchorage over the silk layer of the gallery. Of the several basitarsal characters, the only one used in the literature to distinguish families (and sometimes genera) is the presence or absence of a medial bladder. Other characters (used previously in Szumik, 1994, 1996) were included here, such as the

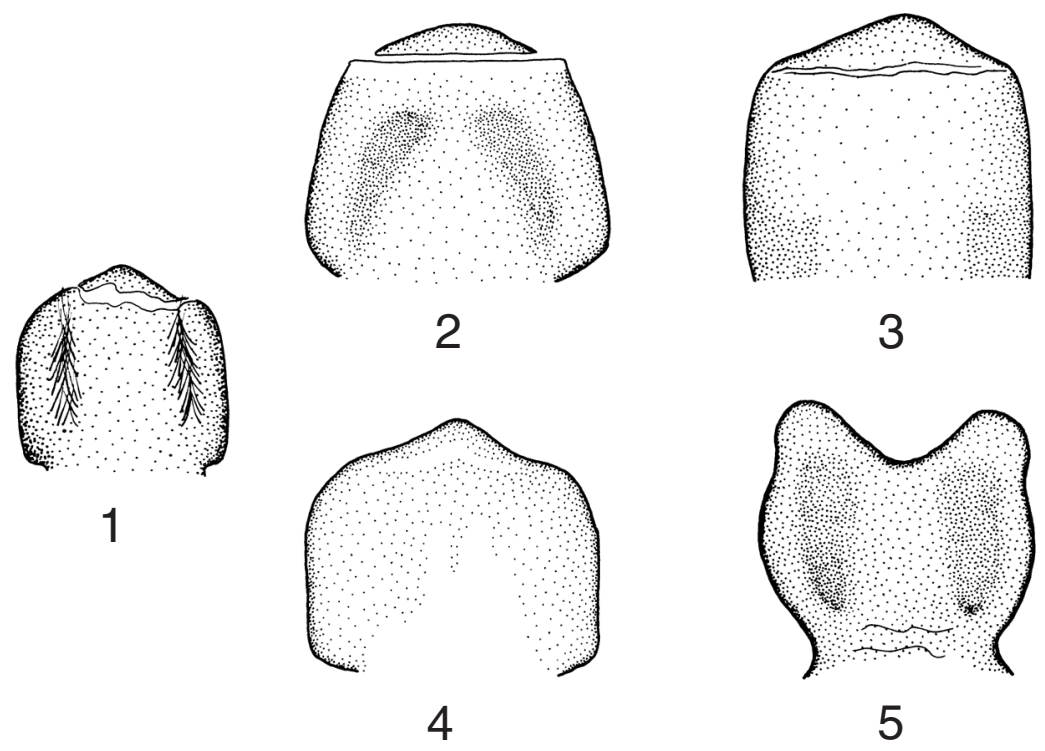

Figs 1-5. Mentum + submentun. 1, Archembia kotzbaurei; 2, Archembia spB; 3, Ochrembia wagneri; 4, Biguembia copo; 5, Pararhagadochir schadei. 


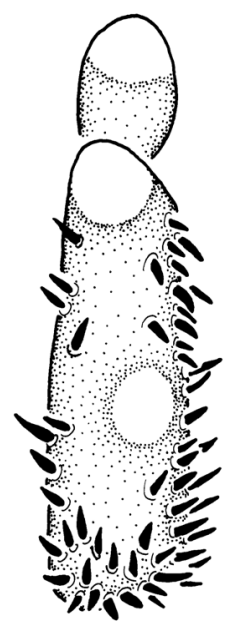

6

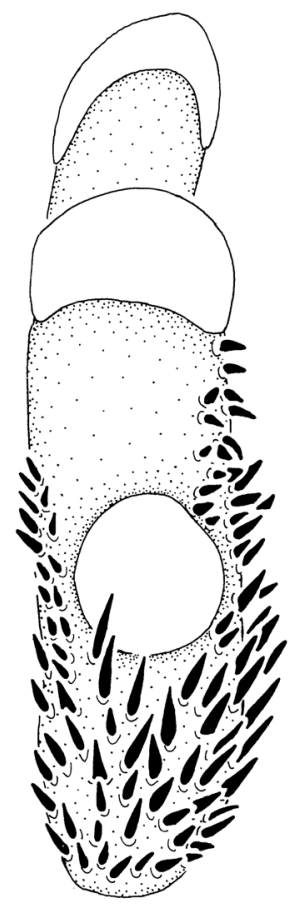

7
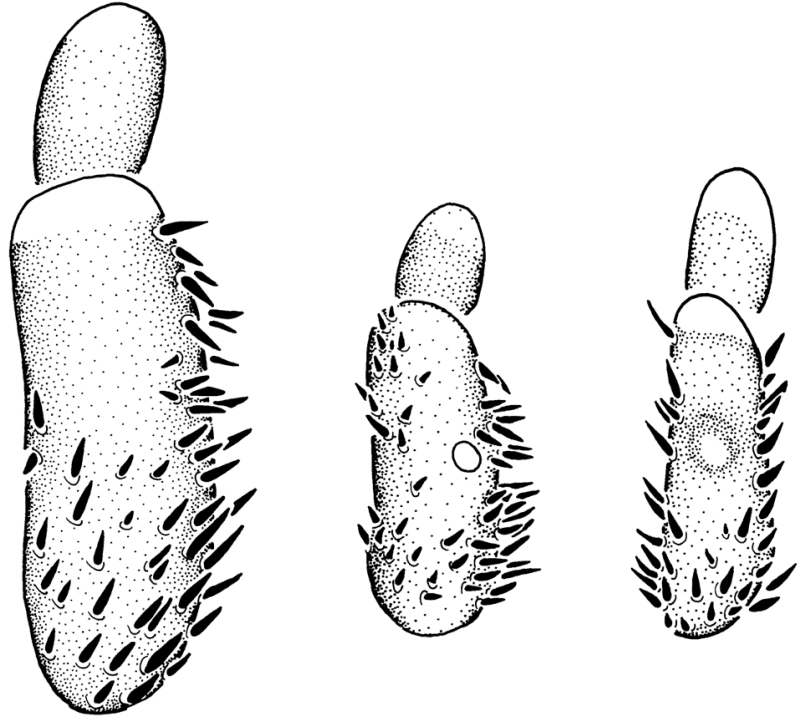

8
9

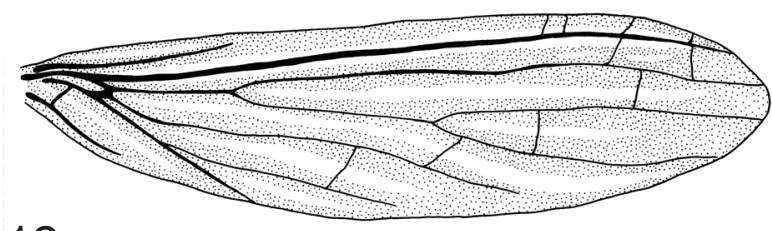

12

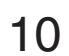

Figs 6-10. Hind basitarsus, male. 6, Archembia batesi; 7, Gibocercus urucumi; 8, Pararhagadochir flavicollis; 9, Pararhagadochir christae; 10, Malacosembia tucumana.

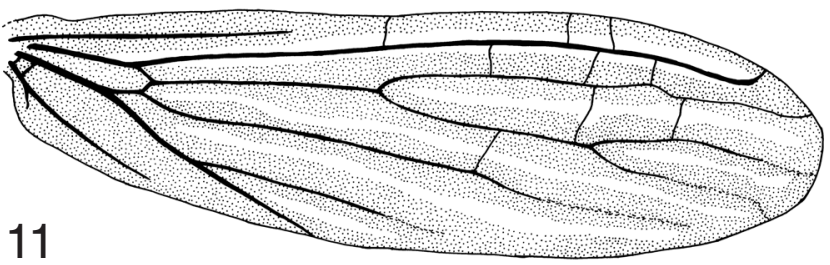

11
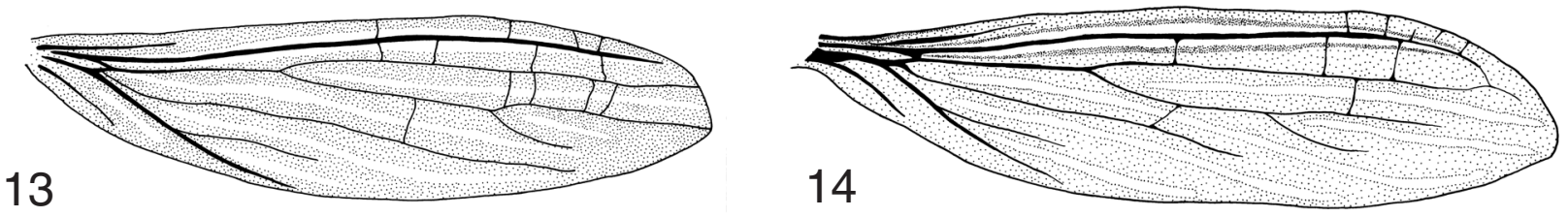

15

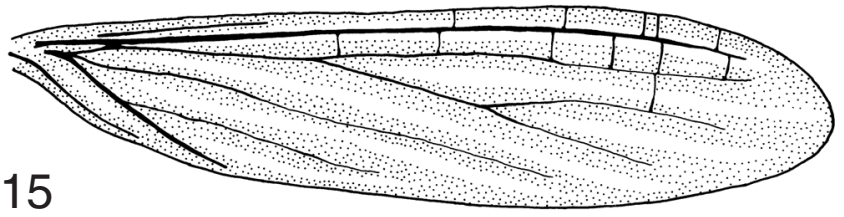

Figs 11-15. Wing. 11, Archembia kotzbaurei; 12, Biguembia copo; 13, Gibocercus urucumi; 14, Pararhagadochir confusa; 15, Malacosembia tucumana. 


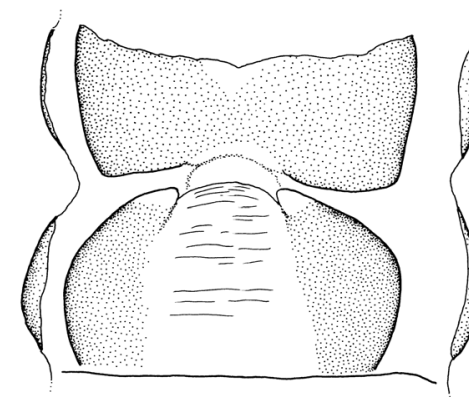

16

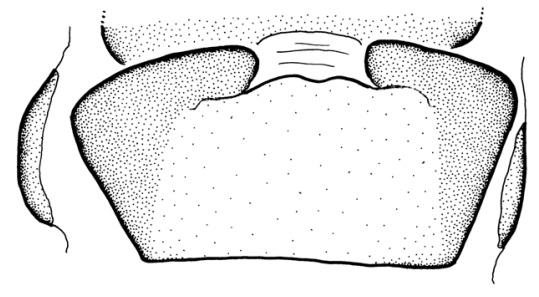

17

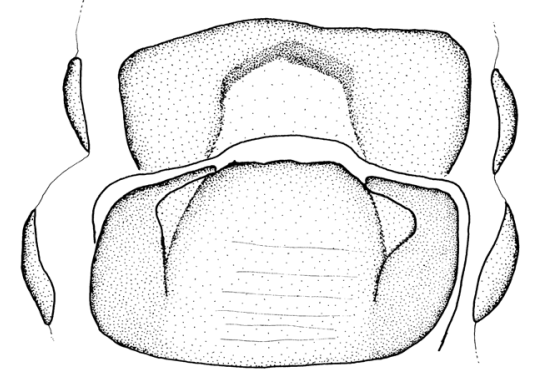

18

Figs 16-18. Female terminalia, eighth and ninth sternites. 16, Biguembia copo; 17, Pachylembia taxcoensis; 18, Archembia kotzbaurei.

setae, apical bladder, and the position of the medial bladder (Figs 6-10).

Wings (nineteen characters, males). Wing venation (Figs 11-15) has in general been poorly studied in Embiids. The wing characters most often mentioned in descriptions are the absence or presence of wings, and whether the Ma and $\mathrm{Cu}$ veins are forked or simple.

The number of transversal veins is often variable at the population level (Ross, 2000, 2001; pers. obs.), and even between the wings of the same individual (pers. obs.). Although the exact number of veins is variable, the presence or absence of a type of vein is much less variable or not variable at all. For example, the origin of the Rs + Ma and Mp veins described in Szumik (1996) distinguishes major groups of Embiidina and presents almost no variation. Several venation characters of this type were therefore included in the present analysis: the degree of development of longitudinal veins, whether they reach wing margins, and the presence or absence of transversal veins.

Some characters used here refer to the absence of certain transversal veins; it must be noted that this varies independently of the general reduction of longitudinal veins, thus suggesting that the two types of character are not correlated.

Terminalia (fifty-five male characters, one female character). The Embiidina lack an ovipositor; the eighth sternite is in general partly divided caudally into two small lateral lobes (called first valvifers) and between them there is a slightly corrugated plate, centrally not pigmented and with two strongly pigmented lateral bands. This is the condition common to most Embiidina, and to all Archembiidae. The lateral lobes of Archembiidae can vary in their degree of fusion with the central plate (Figs 16-18).

Given how copulation is achieved, the male terminalia have a great variety of processes and structures which hold the female abdomen and open the genital opening of the female (Figs 19-42). Most of the ordinal classification is based on these characters.

\section{Results}

PEE-WEE found two optimal trees (strict consensus in Fig. 43); of the 1500 ratchet iterations (see Materials and methods), 488 found the optimal trees. These trees have a fit of 500.0 (36\% of rescaled fit, and 540 steps long). Given that fifteen of the fifty-seven species analysed here have been scored only on the basis of the literature (thus having a significant proportion of missing entries and doubtful scorings), some artefacts could be introduced into the analysis. To make sure that this is not the case, those fifteen taxa were eliminated from the matrix; the results of analysing such a reduced matrix were almost identical to the results for the full data (Fig. 44 shows the strict consensus for the taxa shared in both datasets).

The American and some African genera form a monophyletic group (Fig. 43), grouped by eight synapomorphies (discussed below, in the family description); the group has a very high support (Fig. 45).

Ross (2001) stated that some characters (wing venation and the hind basitarsus) are too variable to be used in either the lower or higher classification of Embiidina. To ensure that those potentially misleading characters were not affecting the results, the data matrix was also run excluding all those characters. Optimal trees found without basitarsal characters were almost identical to trees for the full data, differing only in the position of Malacosembia and Ischnosembia surinamensis (with Malacosembia as the sister group of Pararhagadochir and Ischnosembia surinamensis as the sister group of Aphanembia + Biguembia + Gibocercus $)$. The only two groups differing in the analyses including and excluding those 'variable' characters have very low support under jackknifing (Fig. 45), and therefore the difference is trivial. When the wing characters were excluded instead, some optimal trees had the same resolution as the trees for the full data, others differed only in having Litosembia as the sister group of Rhagadochir (again, the position of Litosembia is very weakly supported; Fig. 45). Finally, the influence of the colour characters was evaluated 

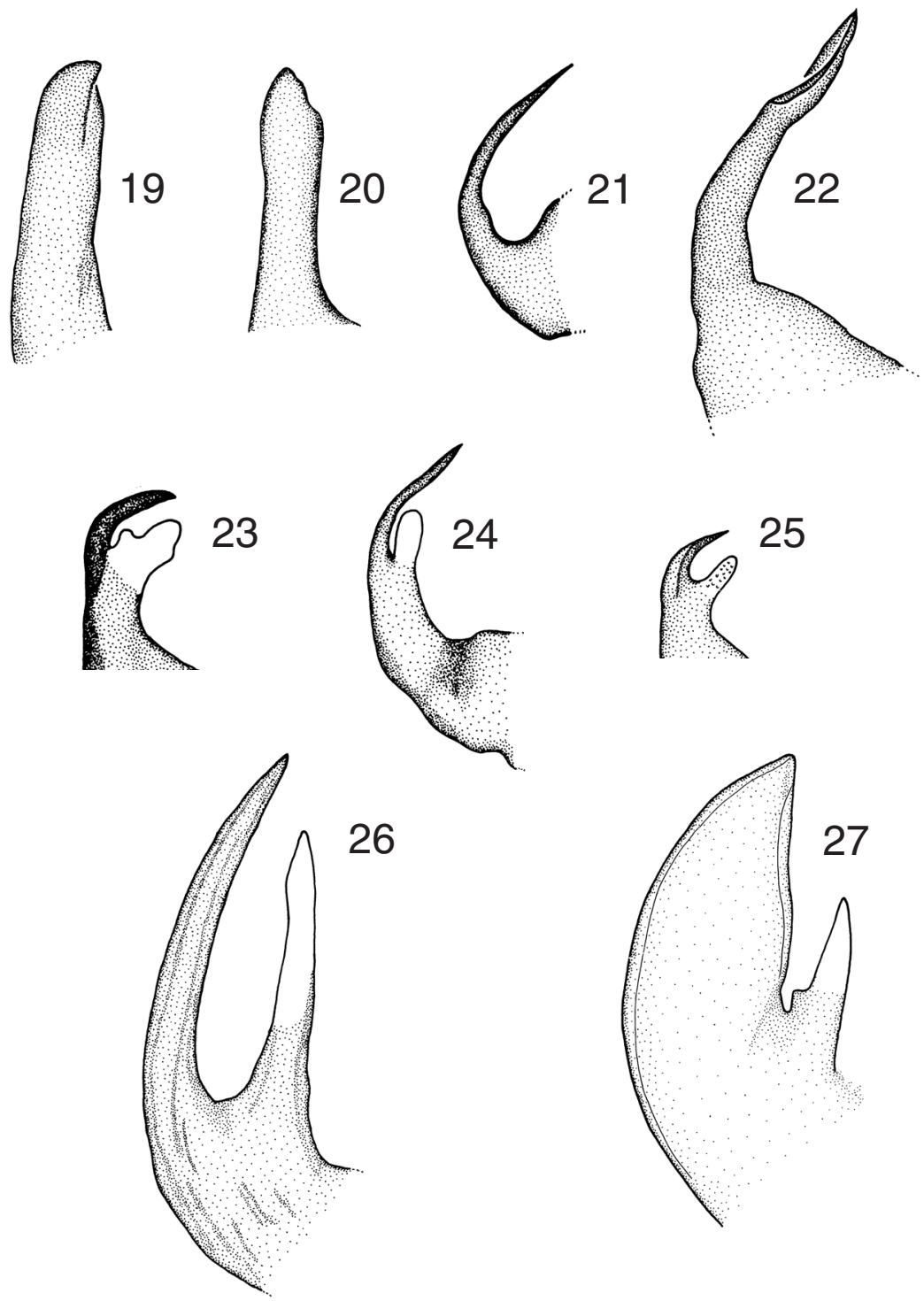

Figs 19-27. Caudal process of the left hemitergite. 19, Archembia kotzbaurei; 20, Archembia spA; 21, Conicercembia tepicensis; 22, Ochrembia wagneri; 23, Pararhagadochir birabeni; 24, Pararhagadochir trachelia; 25, Malacosembia tucumana; 26, Biguembia cocum; 27, Gibocercus urucumi.

by excluding them; some of the resulting trees were identical to the trees for the full data, others differed only in the apical resolution of Gibocercus (with Gibocercus chaco as the sister of Gibocercus urucumi).

\section{Archembiidae, new status}

Diagnosis

Archembiidae is distinguished from the remaining families by the $10 \mathrm{~T}$ with a membranous area occupying the base and centre of the sclerite and most of the base of the $10 \mathrm{R}$, the $10 \mathrm{R}$ and $10 \mathrm{~L}$ connected by a thin basal bar;
10Rp2 present, bar-shaped and well sclerotized. It is distinguished from Embiidae by the depressed mandibles, with incisive and molar areas clearly differentiated (instead of concentrated apically; note that the molars can be lost in some species of Rhagadochir).

\section{General features}

Medium to large sized individuals (6-18 $\mathrm{mm}$ total length). Hind basitarsus robust, medial bladder generally present (absent in Pararhagadochir flavicollis (Enderlein), Ambonembia amazonica (Ross), Pararhagadochir surinamensis Ross, and males of Litosembia Ross), apical bladder more 

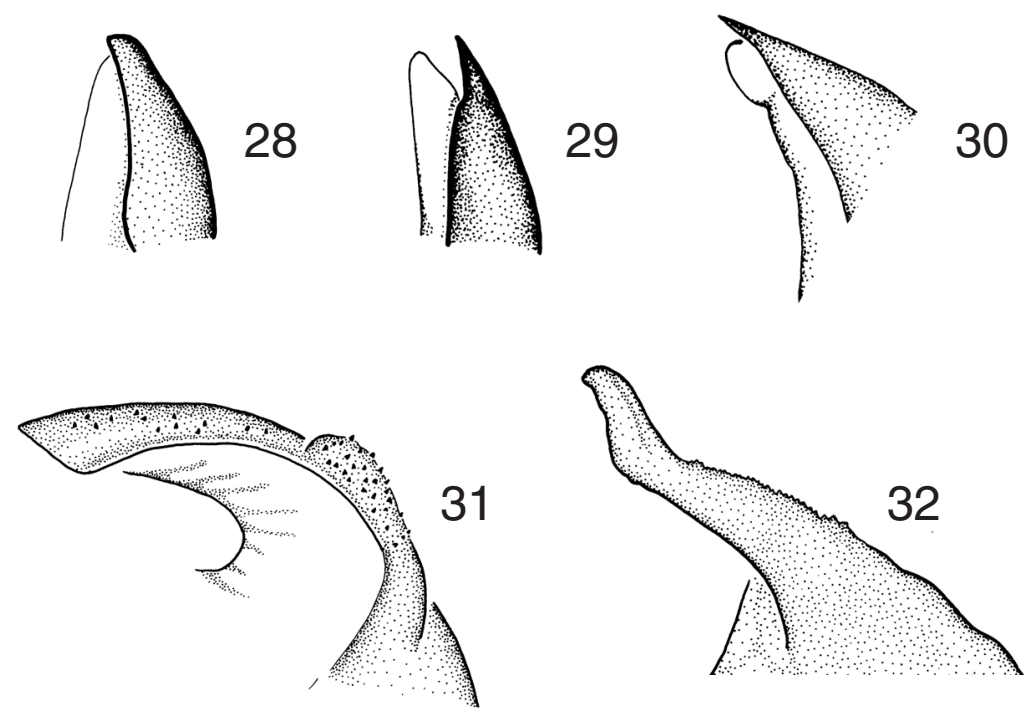

Figs 28-32. Caudal process of the right hemitergite. 28, Pachylembia taxcoensis; 29, Conicercembia tepicensis; 30, Pararhagadochir trachelia; 31, Biguembia cocum; 32, Gibocercus urucumi.

or less developed. Hind basitarsus chaetotaxy: one to two rows in retrolateral face, one to six rows in prolateral; no setae around middle bladder or between middle and apical bladders.

\section{Males}

Mandibles more or less robust, incisives 3-2, molars 2-1 or $1-1$. Mm normally sclerotized, $\mathrm{Sm}$ with anterior margin straight (Fig. 2) or concave (Fig. 5). Winged; apterism at the population level (as in Pararhagadochir trachelia (Navas) or Neorhagadochir salvini (Mac Lachlan)) or generic level (i.e. Pachylembia Ross). Ma forked (except in Archembia arida Ross and Calamoclostes albistriolatus Enderlein), $\mathrm{Cu}$ simple or forked; cross-veins more or less numerous (Figs 11-15). 10Rp1 and 10Lp1 present, with apex simple (Figs 19-22) or forked (Figs 23-27). Epiproct rodlike (but some differences in shape are present), free (fused to the $10 \mathrm{Rp} 2$ only on Archembia, Calamoclostes, Ecuadembia gen.n. and Litosembia). Lpp well developed, partially (Fig. 33) or totally (Figs 34, 35) sclerotized, microtrichia present or not, sometimes with a nodule or a carinate hook in the inner caudal angle of the sclerite (Figs 34, 35). Rpp reduced and mostly fused to the Hp. Hp well developed, carinae normally present; some genera like Pararhagadochir Davis, Rhagadochir, Gibocercus Szumik, Biguembia Szumik, etc., Hp is rectangular, centred and with the caudal margin membranous (Figs 34, 35). LC1 and RC1 cylindrical, except in Neorhagadochir Ross where LC1 is conical (Fig. 36). LC1dp present (absent in Neorhagadochir and some species of Pachylembia), with variable shape (Figs 37-42), with numerous setae (absent in the Mexican genera, Figs 37 , 38). LC1bp normally absent, present in some species of
Pachylembia, Biguembia and Gibocercus (Fig. 41, see Szumik, 1998b: 142).

\section{Females}

Commonly the $1^{\circ} \mathrm{Vfs}$ are differentiated from the central plate by two notches on the caudal margin and by the degree of pigmentation (Fig. 16); in the Mexican taxa, the $1^{\circ} \mathrm{Vfs}$ are well-developed lobes (Fig. 17); also in some females of Archembia the $1^{\circ} \mathrm{Vfs}$ are well differentiated of the central plate (Fig. 18).

\section{Relationships}

The monophyly of Archembiidae is supported (Fig. 43) by the depressed mandibles, with molar and incisive teeth well differentiated (character 2), the Cua diffuse (character 25), cross-veins absent between Ma1 and Ma2 (character 35), the LC1 with setae on the apical area (character 40), the 10T divided into two subdistinct plates (character 49), the 10Lp shaped as a flat bar (character 54), the $10 \mathrm{R}$ with a small membranous base (character 67), and the 10Rp2 bar-shaped (character 79); some of these characters have a medium or high fit (Appendix 4).

Within Archembiidae, three main groups can be distinguished. One group has Archembia and Calamoclostes ('A' in Fig. 43), with very high support (Fig. 45); Archembia appears as paraphyletic in terms of Calamoclostes. The second group ('B' in Fig. 43) has medium support (Fig. 45) and is defined by the 10Lp1 simple, curved and externally laminate (character 56, see Appendix 4). This group comprises nine genera (seven of which are monotypic); eight of 


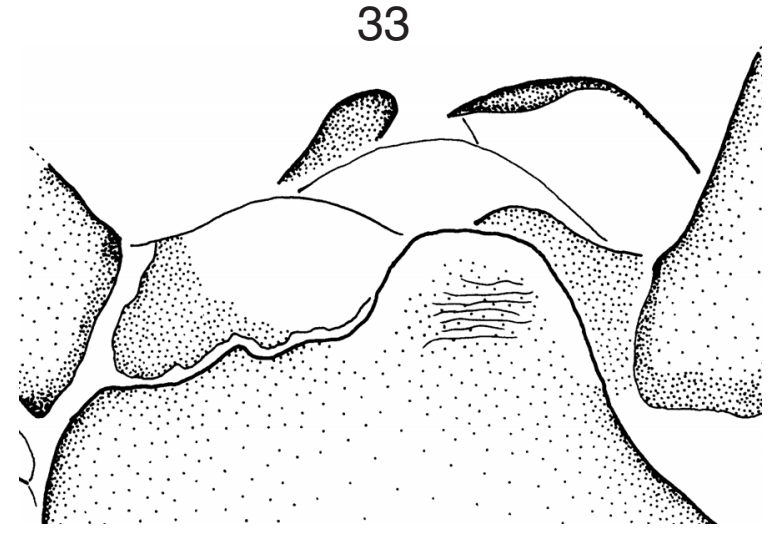

34

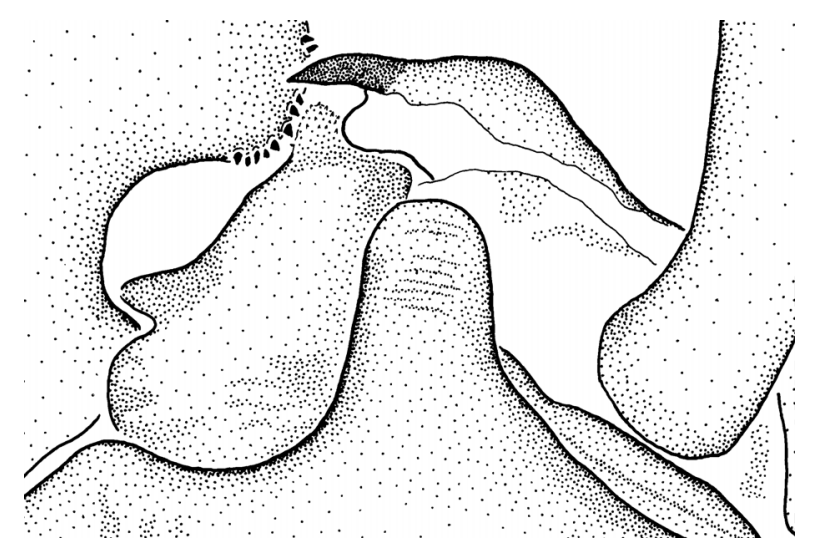

35

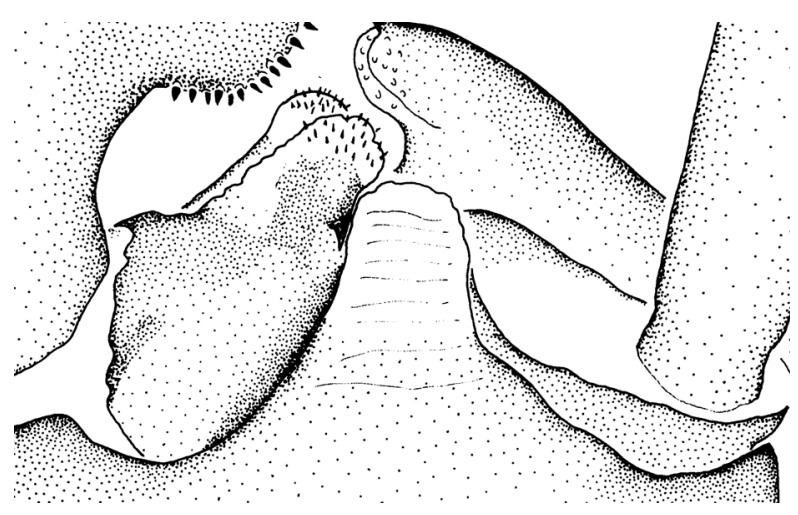

Figs 33-35. Male terminalia, ventral view, process of the hypandrium and left paraproct. 33, Archembia kotzbaurei; 34, Pararhagadochir confusa; 35, Pararhagadochir trachelia.

these genera belong to Ross' (2001) Scelembiinae and the ninth genus (Pachylembia) constitutes, according to Ross, the monotypic subfamily Pachylembiinae. The genus Pachylembia has very high support (Fig. 45); Ross (2001) elevated the genus to subfamily because of its numerous autapomorphies, but the genus also has characters which clearly ally it with other Mexican genera, such as Neorhagadochir and Conicercembia Ross. The third and last group ('C' in Fig. 43), with high support (Fig. 45), comprises nine genera, which share the shape of the 10Lp1 (characters 53, 54, 55), and rectangular and centred Hp (Figs 34, 35; character 83). Two genera in this group appear as nonmonophyletic: Scelembia is paraphyletic in terms of Rhagadochir (Fig. 43); the paraphyly of Scelembia is strongly supported by the data (Fig. 45) and, therefore, Scelembia is proposed as a junior synonym of Rhagadochir. The other nonmonophyletic genus is Ischnosembia Ross, with its type species, Ischnosembia amazonica, more closely related to Ambonembia Ross than to Ischnosembia surinamensis; Ischnosembia is therefore proposed as a junior synonym of Ambonembia and Ischnosembia surinamensis transferred back to Pararhagadochir.

Given that most groups in the present analysis are very stable, the name Archembiidae, new status, is proposed; the composition of the Archembiidae, however, is quite changed from Ross' concept. The three subfamilies proposed by Ross (2001) are rejected, because they bear no possible correspondence with the groups of Archembiidae.

\section{Distribution and composition}

The family includes eighteen genera, with sixty-nine species (in America and Africa). In America they are found from central Mexico to central Argentina; some genera have a very restricted distribution (Pachylembia, exclusively Mexico) and others have a wider distribution (Pararhagadochir, present in most of South America). These data, however, are not very reliable, as many species are known only from the type locality, and there are vast regions where the order has not been collected. The African genera Rhagadochir and Navasiella occur in Tanzania, Uganda, Angola and Congo. Three other African genera of Embiidae (Chirembia Davis from Ethiopia, Parachirembia Davis from Nigeria, and Macrembia Davis from Congo), will possibly have to be transferred to Archembiidae when additional material becomes available.

Archembia Ross, 1971 (Figs 1, 2, 6, 11, 18-20, 33, 39)

Archembia Ross, 1971: 30, 2001: 4; Szumik, 1996: 51, 1998a: 34, 1998b: 141, 2002: 444. Type species: Archembia lacombea (syn.n. of Embia kotzbaueri Navas, 1925).

Diagnosis. Differs from Calamoclostes and Ecuadembia by having the incisive teeth concentrated in the apex of the mandible (character 4), the apical cercus segments longer than the basal segments (character 38), and the medial LC1dp (Fig. 39; character 42).

Relationships. Ross (1971) originally included Archembia in Embiidae, although considering it as 'closer to 


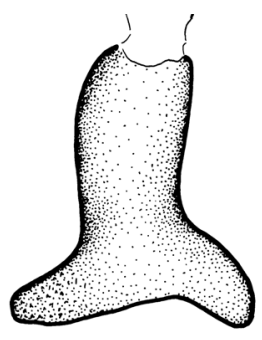

36

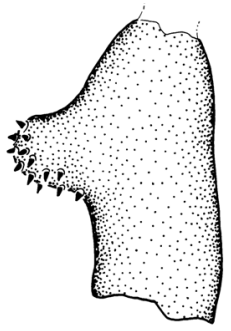

39

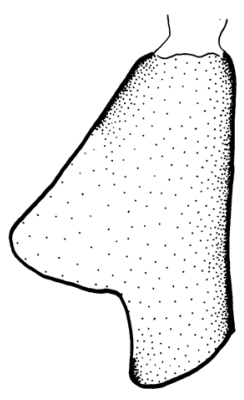

37

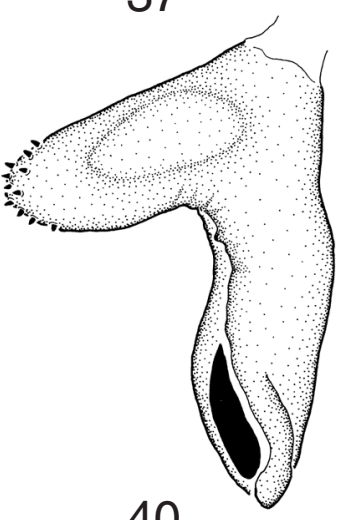

40

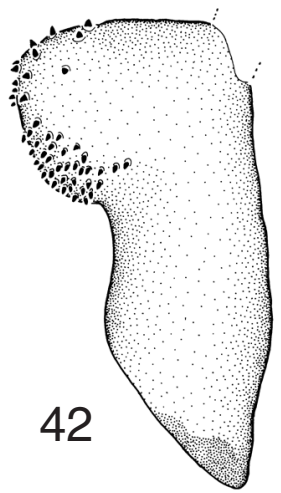

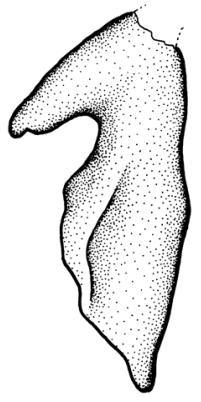

38

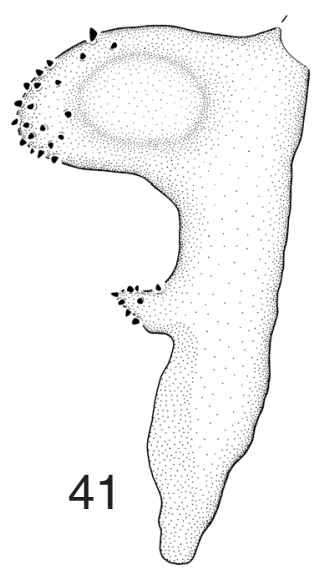

Figs 36-42. Basal left cercus. 36, Neorhagadochir salvini; 37, Pachylembia taxcoensis; 38, Conicercembia tepicensis; 39, Archembia kotzbaurei; 40, Gibocercus nanai; 41, Gibocercus urucumi; 42, Ochrembia wagneri.

Clothodidae' (Ross, 1970, 1971, 2001) than to Embiidae. The characters shared between Clothodidae and Archembia are actually plesiomorphies (as discussed elsewhere; Szumik, 1996, 1998b). The group formed by Archembia and Calamoclostes (Fig. 43) is distinguished clearly by the type B vein origin (Fig. 11; character 20), the large anal region (Fig. 11; character 21), the straight 10Lp1 with a spatulate apex (Figs 19, 20; character 58), and the Ep fused to the 10Rp1. Excepting Archembia arida, both Archembia and Calamoclostes are well-defined genera, and therefore Archembia arida is excluded from Archembia (see under Ecuadembia).
Composition and distribution. Until recently, Archembia had only three species, A. kotzbaueri, A. lacombea, and $A$. batesi (MacLachlan), known only from their type localities in Brazil. Ross (1971) transferred Embia kotzbaueri Navas (described on the basis of a male from Rio de Janeiro) to Archembia, based on the original description (the type is lost). Ross (1971: 32) also described type species of Archembia, A. lacombea, from Rio de Janeiro, mentioning that two species coexist in Rio de Janeiro, the lighter-coloured lacombea and a darker one, possibly kotzbaueri. These two are distinguishable only by the degree of pigmentation, but given the individual variability in the pigmentation (see 


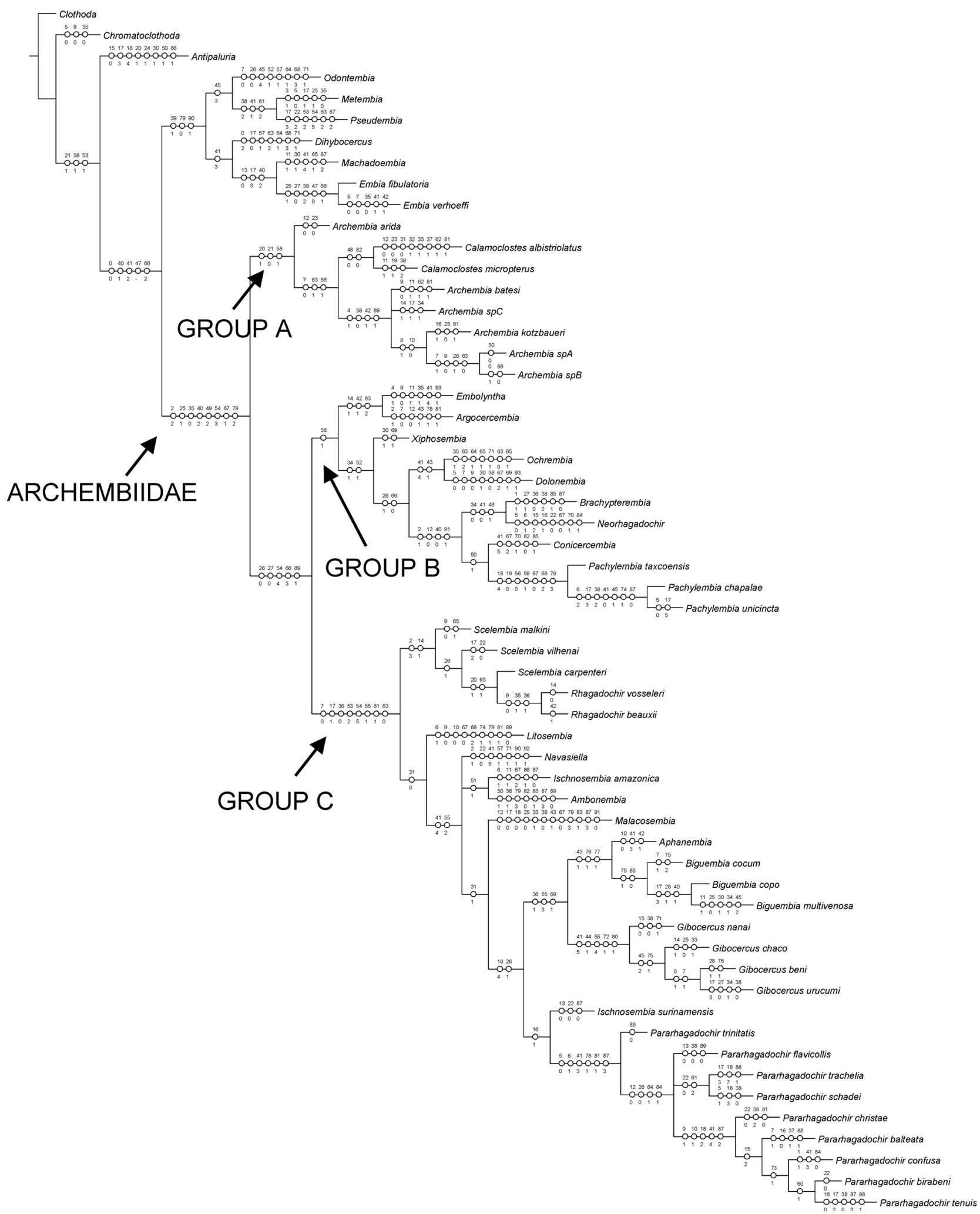

Fig. 43. Consensus of the two optimal trees. 
discussion of 'Characters'), the distinction of a new species on the basis of this character alone seems unjustified. Having studied specimens of Archembia lacombea (paratypes) and other specimens recently collected in Rio de Janeiro and São Paulo, I conclude that there is only one species in the area, and therefore synonymize Archembia lacombea with Archembia kotzbaueri. Ross (2001) has recently described another six species, $A$. boliviana (Bolivia), A. peruviana (Peru), A. bahia, A. dilata, A. paranae (Brazil), and $A$. arida (Ecuador). Here again, two species, Archembia peruviana and the long known Archembia batesi, are distinguished solely by coloration. Having studied the type of Archembia batesi, as well as specimens from Peru matching Ross' description of Archembia peruviana, I found no difference and synonymize Archembia peruviana with Archembia batesi. The cladistic analysis includes three species of Archembia (identified as spA, spB and $\mathrm{spC}$ ), which could perhaps be A. boliviana, A. bahia, A. dilata or A. paranae (all

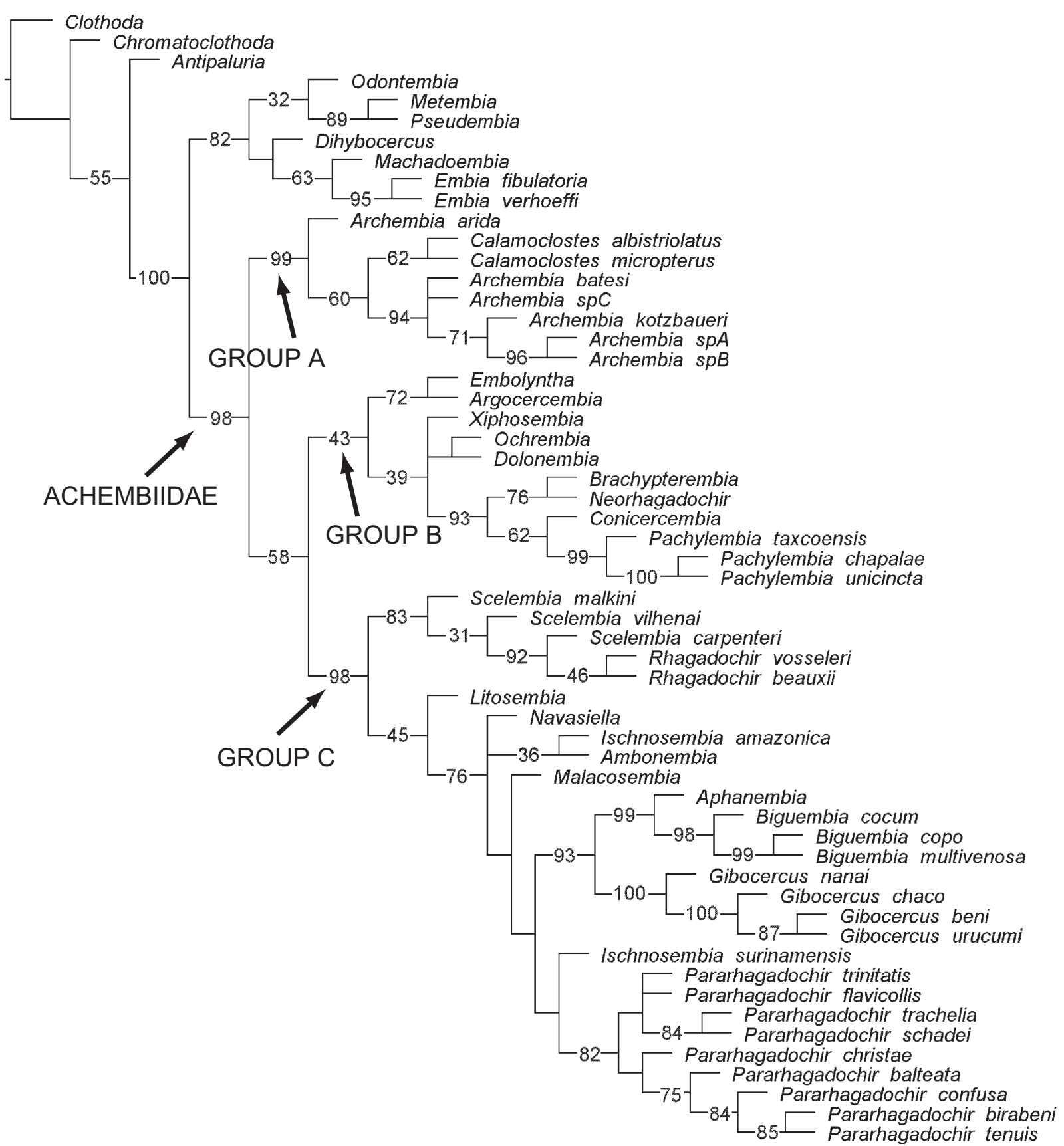

Fig. 44. Jackknifing tree (see methods), unnumbered nodes have support below 30 . 


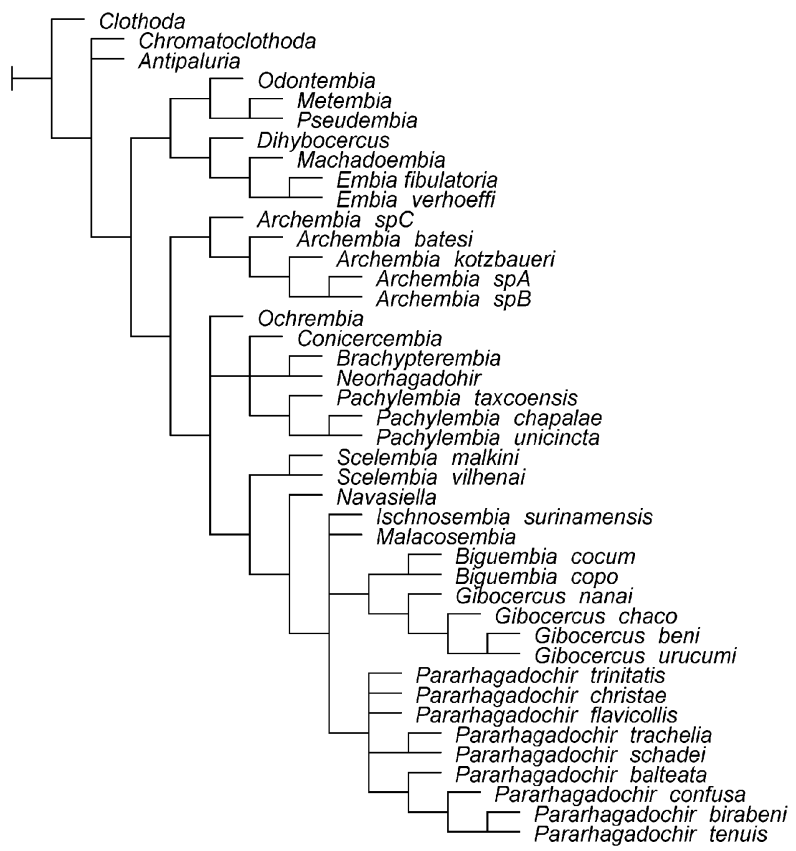

Fig. 45. Consensus of the optimal trees with and without the fifteen taxa scored on the basis of the literature.

described by Ross, 2001); these species were not illustrated, and the description provides data only on coloration. Based on geographical distribution alone, spB is possibly Archembia dilata, and spA and spC may be Archembia bahia and Archembia paranae, respectively. The distribution of Archembia is poorly understood, as all the species are known from one or two localities, but it seems likely that (as conjectured by Ross, 1971) it occurs in the Amazon area, eastern Brazil, and tropical forests of Peru and northeastern Argentina.

Calamoclostes Enderlein, 1909

Calamoclostes Enderlein, 1909: 188, 1912: 27; Krauss, 1911: 73; Navas, 1918: 94; Davis, 1940a: 189; Ross, 1944: 414; 2001: 17. Type species: Calamoclostes albistriolatus.

Diagnosis. Calamoclostes can be distinguished from Archembia and Ecuadembia by having the sclerotic discoidal area on the 9T (character 48), the tip of the 10Lp1 strongly curved and acute. Calamoclostes differs from Archembia by having the LC1dp apical (medial in Archembia).

Relationships. Because Calamoclostes is a uniform genus, only two species (C. albistriolatus and C. micropterus) were used to test the monophyly and the relationships with Archembia. Ross (2001) claimed that the species of Calamoclostes are derived from the genus Archembia because, according to him, Archembia has more plesiomorphic morphological and behavioural characters. Although Ross states that there is only one female per nest in Calamoclostes, and more than one in Archembia, only one female was observed per nest in Archembia spB from Argentina (Szumik, pers. obs.). In the cladistic analysis, Calamoclostes is supported as monophyletic (Fig. 43) by having the sclerotic discoidal area on the 9T (character 48) and the $\mathrm{Hp}$ without transversal keels (character 82), with high and medium fit, respectively (Appendix 4).

Composition and distribution. Calamoclostes contains six species: C. albistriolatus Enderlein, C. auriceps Ross, C. micropterus Ross, C. silvestris Ross (Ecuador), C. gurneyi Ross and C. oculeus Ross (Colombia); all species are known from the type locality only (Ross, 2001).

Ecuadembia n.gen.

Type species: Archembia arida Ross.

Diagnosis. Ecuadembia can be distinguished from Archembia and Calamoclostes by having the Lpp completely sclerotized and the 10Lp1 tip without any carinae; Ecuadembia differs from Archembia by having the incisive teeth well developed and not concentrated on the apex, the LC1dp with apical position (medial in Archembia), apical and basal cerci with the same length (apical cerci longer than basal cerci in Archembia) and apical antennal segments of the females coloured (not pigmented in Archembia).

Relationships. Ecuadembia lacks the numerous synapomorphies which define the genus Archembia and the resultant grouping of (Calamoclostes + Archembia). Ecuadembia justifies the new genus for Archembia arida to avoid paraphyly of Archembia.

Composition and distribution. Contains just one species Ecuadembia arida (Ross) from Ecuador.

Embolyntha Davis, 1940

Olyntha Gray, 1832: 347. Type species: Olyntha brasiliensis Gray.

Embius Gray, 1832: 786.

Embolyntha Davis, 1940b: 344 (Embius and Olyntha preoccupied names); Ross, 1944: 412, 1971: 29, 2001: 26; Szumik, 1998a: 34, 1998b: 141.

Argocercembia Ross, 2001: 63. syn.n. Type species: Argocercembia guyana.

Diagnosis. Embolyntha can be distinguished from other Archembiidae by having the 10Lp1 simple and starting at the inner caudal angle of the 10L (at the inner anterior angle in Xiphosembia, some species of Ochrembia and the Mexican genera), the $10 \mathrm{Lp} 1$ leaflike with many longitudinal carinae.

Relationships. Embolyntha brasiliensis and the monotypic genus Argocercembia are grouped by sharing the 10Lp1 
shape (see diagnosis, character 63), the medial bladder on males small (character 14) and the LC1dp with medial position (character 42, a condition also present in Archembia), these synapomorphies have low fit (Appendix 4) but the group has high support (Fig. 45). Because the differences between Embolyntha and Argocercembia are insignificant and because the group is well supported, Embolyntha should now be considered a senior synonym of Argocercembia.

Composition and distribution. Embolyntha has two species: Embolyntha brasiliensis from Brazil (without any specific location) and Embolyntha guyana (Ross) from Guyana (Ross, 2001).

Xiphosembia Ross, 2001

Xiphosembia Ross, 2001: 28. Type species: Xiphosembia amapae.

Relationships. As no material was made available to be examined, data were derived from Ross (2001). Ross did not mention a possible association of Xiphosembia with other genera; the diagnosis was purely descriptive. Xiphosembia has a character combination such that one possible placement would be between the group of (Archembia + Calamoclostes) and the grouping of the Mexican genera (Neorhagadochir (Conicercembia Pachylembia)). This genus shares with Neorhagadochir and Conicercembia the shape of the 10Lp1 and with Archembia the form of the LC1dp. In the analysis, Xiphosembia is the sister group of ( Ochrembia Dolonembia) (Conicercembia (Neorhagadochir (Pachylembia)))), by having the 10Lp1 starting from the inner anterior angle of the $10 \mathrm{~L}$ (character 52), synapomorphy with maximum fit (Appendix 4).

Composition and distribution. The monotypic genus comes from one locality of the state of Amapa (Brazil) from the Amazon Basin.

Ochrembia Ross, 2001 (Figs 3, 22, 42)

Ochrembia Ross, 2001: 73. Type species: Embia wagneri Navas.

Diagnosis. Can be differentiated from other genera by having the 10Lpl tubular with the tip acute and excavate (Fig. 22) and the 10Rp2 inconspicuous.

Relationships. Ochrembia is grouped with Dolonembiaanother monotypic genus of Ross - by sharing the LC1dp squared and depressed (Fig. 42; characters 41 and 43), a condition also present in Embolyntha guyana, Malacosembia and Biguembia. Some synapomorphies of Ochrembia, like the depression between the 10Lp1 and 10L (character 64), the internal anterior angle of the $10 \mathrm{~L}$ excavated (character 65) and the $\mathrm{Hp}$ centred, lobed, with margins not sclerotized (character 83), are also present in the most apical group of the cladogram (Rhagadochir, Pararhagadochir, etc.)

Composition and distribution. Ochrembia is a monotypic genus known from three localities of the dry Chaco of the northwest of Argentina (Szumik, pers. obs.).

Dolonembia Ross, 2001

Dolonembia Ross, 2001: 30. Type species: Dolonembia tapirape Ross.

Relationships. As no material was made available to be examined, data were derived from Ross (2001). Ross (2001: 30) distinguished the males of Dolonembia from the 'distant' Xiphosembia by the larger size (but the male of Xiphosembia has $8-12 \mathrm{~mm}$ total length and the unique male of Dolonembia has $11.5 \mathrm{~mm}$ total length) and by having dark coloration, the mandibles robust (also in Xiphosembia), the caudal margin of the $10 \mathrm{~L}$ convex and the $10 \mathrm{Lp}$ starting at the posterior inner angle of the 10L (also in Xiphosembia). In consequence Dolonembia can be differentiated from Xiphosembia only by coloration and by the shape of the caudal margin of the $10 \mathrm{~L}$. Dolonembia groups with Ochrembia (Fig. 43) by bearing the LC1dp depressed (character 43), a character with medial fit (Appendix 4), but this group has no support under jackknifing (Fig. 45). Both Dolonembia and Xiphosembia were scored as ambiguous for many characters, and probably the position of these genera will change in the future.

Composition and distribution. The unique species of Dolonembia was described from one locality in Mato Grosso, Brazil.

Neorhagadochir Ross, 1944 (Fig. 36)

Neorhagadochir Ross, 1944: 418, 1984: 4, 2001: 75; Szumik, 1996: 55, 1998b: 141, 2002: 444. Type species: Neorhagadochir inflata.

Brachypterembia Ross, 1984: 7, 2001: 76; Szumik, 1998b: 141, 2002: 444. syn.n. Type species: Brachypterembia moreliensis.

Diagnosis. Neorhagadochir can be differentiated from the other genera of Archembiidae by having the LC1 base conical and with microtrichiae.

Relationships. Neorhagadochir forms, together with the monotypic genus Brachypterembia, a well-supported group (Fig. 43); one of the most striking synapomorphies is the LC1 conical (Fig. 36; character 46). Both genera differ only in small details and Brachypterembia is proposed here as a junior synonym of Neorhagadochir.

Neorhagadochir is the sister group of Conicercembia and Pachylembia (Fig. 43) by bearing the poorly conspicuous 
molar teeth (character 2); the female with apical antennal segments coloured (character 12); the LC1 setae absent (character 40) and the Ep broad, sclerotized plate shape (character 91); these synapomorphies have medium fit (Appendix 4).

Composition and distribution. The central American genus contains three species: Neorhagadochir inflata Ross (Guatemala), Neorhagadochir salvini (MacLachlan) known from south of Mexico to Costa Rica (Ross, 1984; Szumik, 2002) and Neorhagadochir moreliensis (Ross), new combination (known from a single locality in Michoacan, Mexico).

Conicercembia Ross, 1984 (Figs 21, 29, 38)

Conicercembia Ross, 1984: 10, 2001: 6; Szumik, 1996: 55, 1998b: 141, 2002: 444. Type species: Conicercembia tepicensis.

Diagnosis. Conicercembia can be distinguished from Neorhagadochir by having the LC1 tubular (conical in Neorhagadochir), the LC1dp (absent in Neorhagadochir) long and acute with a notch on the apex and without setae (Fig. 38), the basal area of the 10R membranous and well defined (reduced in Neorhagadochir). Conicercembia can be differentiated from Pachylembia by having the 10Rp1 (Fig. 29) forked and acute, and the ventral tip of the 10Rp1 well developed (longer than the dorsal tip).

Relationships. Conicercembia has many autapomorphies not included in the analysis because they are not informative at this level (see diagnosis). Conicercembia is the sister group of Pachylembia (Fig. 43), sharing the 10T pilose (character 50), a character with high fit (Appendix 4).

Composition and distribution. Ross (1984) described this Mexican genus for Conicercembia tepicensis Ross; Mariño \& Márquez (1988) subsequently described the same species with the name Clothoda septentrionalis in the family Clothodidae. Ross (2001) transferred septentrionalis to the genus Conicercembia, and considered that septentrionalis differs from his type species tepicensis (Ross, 2001: 76). In studying types for both species I found no difference, and therefore propose $C$. tepicensis as the senior synonym of $C$. septentrionalis (Szumik, 2002). The genus is known from four localities in four states of Mexico: Michoacan, Jalisco, Colima and Nayarit (Ross, 1984).

Pachylembia Ross, 1984 (Figs 17, 28, 37)

Pachylembia Ross, 1984: 13, 2001: 81; Szumik, 1996: 55, 1998b: 141, 2002: 444. Type species: Pachylembia chapalae.

Diagnosis. Pachylembia can be differentiated from other Mexican genera by having the basal area of the $10 \mathrm{R}$ inconspicuous (character 56); the 10Lp1 tiny, hooklike, shorter than half the width of the 10L (character 59); the 10Rp1 simple with apex truncate (Fig. 28; character 68); the 10Rp2 obsolete (character 79) and males wingless (character 19).
Relationships. The monophyletic genus Pachylembia has the maximum support in this study (Fig. 45). The species are grouped by many synapomorphies (Fig. 43, many of those included in the diagnosis). Pachylembia chapalae and Pachylembia unicincta (Fig. 43) share the Sm with anterior margin w-like (character 6), the apical cerci reduced (character 38 ), the LC1 without setae and with a basal node on the inner side (character 45, absent in Pachylembia taxcoensis, but this species has a medial LC1dp, Fig. 37), and the absence of processes on the Lpp (character 87).

Composition and distribution. Exclusive to Mexico, the genus includes five species: Pachylembia chapalae, $P$. taxcoensis, $P$. unicincta, $P$. colimae and $P$. autlanae. The genus is known only from seven localities in Jalisco, Michoacan, Colima and Guerrero (Ross, 1984, 2001; Szumik, 2002).

\section{Rhagadochir Enderlein, 1912}

Rhagadochir Enderlein, 1912: 54; Friederichs, 1934: 406; Davis, 1938: 267, 1940a: 171, 1940c: 533, 1940d: 679; Ross, 1944: 420, 1952: 46, 1960: 301. Type species: Embia vosseleri Enderlein.

Scelembia Ross, 1960: 300; Szumik, 1996: 51, 1998b: 141. syn.n. Type species: Rhagadochir malkini Ross.

Diagnosis. Rhagadochir can be differentiated from other Archembiidae by having the tips of the 10Lp1 completely fused and the external margin of the $10 \mathrm{Rp} 1$ with a strong notch. It can also be distinguished from Pararhagadochir by having the anterior margin of the Sm straight (not concave), the incisive teeth acute (medial ones tiny), and just one molar tooth per mandible (small and inconspicuous).

Relationships. Ross (1960) transferred all but two species of Rhagadochir to his new genus Scelembia; these changes were supported only by differences in coloration. In this analysis, Scelembia appears paraphyletic in terms of Rhagadochir and is well supported (Fig. 45). Because the group is clearly homogeneous, Scelembia must be considered a junior synonym of Rhagadochir.

Composition and distribution. Rhagadochir contains six species: Rhagadochir vosseleri (Enderlein), $R$. carpenteri Davis [Tanzania], $R$. beauxii Davis [Uganda], R. malkini Ross, $R$. vilhenai Ross [Angola] and $R$. virgo (Ross) [Congo]; all the species are known only from the type locality.

Litosembia Ross, 2001

Litosembia Ross, 2001: 58. Type species: Litosembia oligembiodes. 
Relationships. As no material was made available to be examined, data were taken from Ross (2001). This genus has a combination of characters that places it between Rhagadochir and Pararhagadochir. Many of the characters given by Ross (2001: 58) in his diagnosis of Litosembia are also found in other related genera; the characters actually distinguishing Litosembia are the anterior margin of the Sm concave, the small 10Rp2, the Ep free and reduced, the $10 \mathrm{Lp} 1$ with the tips fused, the Lpp without any structure and the absence of the middle bladder of the hind basitarsus. Litosembia shares with Rhagadochir and Pararhagadochir the absence of cross-veins between Rs and Mal (character 31 ).

Composition and distribution. Litosembia contains only one species, L. oligembioides, known only from Belem, Brazil (Ross, 2001).

Navasiella Davis, 1940

Navasiella Davis, 1940a: 177. Type species Oligotoma sulcata Navas.

Diagnosis. Navasiella can be distinguished by having the LC1dp tubular (character 41) with the setae concentrated on the tip, the laminate carinae on the inner tip of the 10Lp1 (character 57), the ventral tip of the 10Rpl sclerotized (character 71). It can also be distinguished from Pararhagadochir and Rhagadochir by the well-developed Rpp (character 90), the fused Ep and 10Rp2 (character 92), and the well-differentiated molar teeth (character 2).

Relationships. The position of Navasiella is well supported (Fig. 45); it is clear that this genus possesses numerous characters to be a member of Archembiidae closely related to Rhagadochir and Pararhagadochir.

Composition and distribution. This genus contains only one species, Navasiella sulcata, described from a single locality in Congo.

Ambonembia Ross, 2001

Ambonembia Ross, 2001: 66. Type species: Ambonembia incae.

Ischnosembia Ross, 2001: 32. syn.n. Type species: Ischnosembia amazonica.

Diagnosis. Ambonembia can be distinguished from Biguembia, Gibocercus and Pararhagadochir (the most closely related genera) by having the $10 \mathrm{~L}$ diagonally elevated and the 10Lp1 with the tips not well separated (as in Teratembiidae).

Relationships. Ambonembia and Ischnosembia amazonica Ross are grouped by having the $10 \mathrm{~L}$ diagonally elevated (character 51, a synapomorphy with the highest fit; Appen- dix 4); both also share the apex of the Ep elevated and the shape of the 10Lp1 (see diagnosis). In spite of the clear similarity between Ambonembia and Ischnosembia, Ross did not comment on their likeness, but compared each one of these genera with a different genus (Ambonembia with Malacosembia and Ischnosembia with Pararhagadochir). Here, I propose Ischnosembia as the junior synonym of Ambonembia.

Composition and distribution. Ambonembia adspersa (Enderlein) from Bolivia, Ambonembia incae Ross from Peru, and Ambonembia amazonica (Ross) from Brazil; all species known only for the type locality from the Amazon Basin.

Biguembia Szumik, 1998 (Figs 4, 12, 16, 26, 31)

Biguembia Szumik, 1998b: 149, 2002: 444; Ross, 2001: 60. Type species: Biguembia copo.

Aphanembia Ross, 2001: 64. syn.n. Type species: Aphanembia obscura.

Diagnosis. Biguembia is a genus clearly distinguishable by having the 10Lp1 with both tips longer (longer than the 10L) and equal (Fig. 26), with the inner tip more sclerotized, the LC1dp depressed (character 43), the 10Rp1 with a longitudinal carinae (character 76 ) and the presence of a convexity on the 10Rp1 (Fig. 31; character 77).

Relationships. The monotypic genus Aphanembia is grouped with Biguembia (Fig. 43) by bearing all the characters mentioned in the diagnosis; this group has the highest support under jackknifing (Fig. 45). The only species of Aphanembia has no distinctive characters to justify its exclusion from Biguembia and, therefore, I propose Biguembia as a senior synonym of Aphanembia.

Biguembia and Gibocercus form a well-supported group (Fig. 45) by having the 10Rp1 with the dorsal tip well developed and the ventral tip very inconspicuous (character 69) and the 10Lp1 with both tips longer (character 55, both characters have minimal homoplasy). These genera are also grouped by the presence of cross-veins between $\mathrm{Ma}$ and $\mathrm{Mp}$ (Fig. 12; character 36), but this condition is also present in other groups of Embioptera.

Composition and distribution. Originally described for two species, Biguembia copo and Biguembia cocum from Argentina and Brazil, respectively (Szumik, 1998b); the genus now includes Biguembia multivenosa Ross and Biguembia obscura (Ross), both from Brazil.

Gibocercus Szumik, 1998 (Figs 7, 13, 27, 32, 40, 41)

Gibocercus Szumik, 1998b: 141, 2002: 444; Ross, 2001: 35.

Type species: Gibocercus chaco. 
Diagnosis. Gibocercus can be distinguished easily by many exclusive characters, such as the tubular form of the LC1dp (Figs 40, 41; character 41), the convexity on the dorsal face of the LC1dp (Figs 40, 41; character 44), the inner tip of the 10Lp1 beaklike and larger, the external tip of the 10Lp1 conic, unsclerotized and smaller (Fig. 27; character 55), the external face of the 10Rp1 strongly depressed (character 72) and the 10Rp2 broad with a discoidal apex (character 80).

Relationships. With the exception of character 41, all the synapomorphies mentioned in the diagnosis have little or no homoplasy (Appendix 4) and the monophyly of the genus is well supported (Fig. 45). Gibocercus nanai is a sister group of the other species of Gibocercus by not having the basal process of the LC1 (Fig. 41), otherwise an autapomorphy of the genus (Szumik, 1998b).

Composition and distribution. Gibocercus was described originally (Szumik, 1998b) with four species: G. chaco, G. urucumi, G. nanai and G. beni from Argentina, Brazil, Peru and Bolivia, respectively. Recently Ross (2001) described another five species: G. peruvianus, G. flavipes [Peru], G. magnus [Bolivia], G. sandrae and G. napoa [Ecuador].

Pararhagadochir Davis, 1940 (Figs 5, 8, 9, 14, 23, 24, 30, $34,35)$

Pararhagadochir Davis, 1940a: 181, 1942: 114; Ross, 1944: 420, 2001: 43; Szumik, 1996: 51, 1998a: 34, 1998b: 141, 2002: 444. Type species: Embia trinitatis De Saussure.

Diagnosis. Pararhagadochir can be distinguished from other Archembiidae by having the anterior margin of the Sm strongly concave (Fig. 5; character 6), the 10Lp1 forked with the internal tip (hook) and the external tip (flat lobe) separated, with both tips always shorter than the width of the 10L (Figs 23, 24). Also, it can be differentiated by the presence of a sclerotized node between the $10 \mathrm{~L}$ and the base of the LC1 (character 84) and the $10 \mathrm{Rp} 2$ with more than one longitudinal laminate keel (character 78).

Relationships. The position of Pararhagadochir surinamensis as a sister group of the other species of Pararhagadochir is not well supported (Fig. 45); in addition, slightly suboptimal trees have this species excluded from the genus Pararhagadochir. Many groups inside the genus have no support because those resolutions are defined by highly homoplastic mandible or wing characters. Only three groups have some degree of support: all the species excluding $P$. surinamensis, is supported by the characters mentioned in the diagnosis, Pararhagadochir birabeni (Navas) + Pararhagadochir tenuis (Enderlein) by having the external tip of the 10Lp1 bilobed (Fig. 23; character 60), and Pararhagadochir trachelia + Pararhagadochir schadei by having the 10Lp1 base longer (Fig. 24; character 61).
Composition and distribution. The genus is known from Colombia to south of Buenos Aires (Argentina). It includes thirteen species: Pararhagadochir trinitatis (de Saussure) from Trinidad and Venezuela, $P$. bicingillata (Enderlein), $P$. christae Ross, $P$. balteata Ross, $P$. minuta Ross from Brazil, P. flavicollis (Enderlein), P. tenuis (Enderlein) from Bolivia, P. schadei Ross from Paraguay, P. birabeni (Navas), P. trachelia (Navas), P. confusa Ross, P. pallida Ross from Argentina and $P$. picchua Ross from Peru. Although Pararhagadochir is the genus with the most species of Archembiidae, many of these species are known only from type locality; a manuscript in preparation considerably enlarges the distribution of many known species.

Malacosembia Ross, 2001 (Figs 10, 15, 25)

Malacosembia Ross, 2001: 70. Type species: Malacosembia tucumana.

Diagnosis. Malacosembia can be distinguished from Pararhagadochir, the genus most closely related to it, by having the Ep and 10Rp2 inconspicuous; the dorsal tip of the 10Rp1 like a depressed hook, well developed, with two or three longitudinal carinae, and the anterior margin of the Sm straight and membranous.

Relationships. Although Malacosembia appears in both optimal trees as the sister group of Pararhagadochir + $($ Biguembia + Gibocercus $)$, the relationship has low support (Fig. 45).

Composition and distribution. The genus contains two species: Malacosembia tucumana from Argentina and Malacosembia yungae from Bolivia. The nests of Malacosembia tucumana are $10-39 \mathrm{~cm}$ in diameter, with numerous tubes crossing over, all covered with a shiny layer of web (Szumik, pers. obs.).

\section{Acknowledgements}

This work was supported by grants PIP CONICET no. 4973 and PICT98 no. 01-04347. The criticisms of Pablo Goloboff, James Carpenter, Fernando Navarro and an anonymous reviewer are deeply appreciated.

\section{References}

Davis, C. (1938) Studies in Australian Embioptera. Part III: Revision of the genus Metoligotoma, with descriptions of new species, and other notes on the family Oligotomidae. Proceedings of the Linnean Society of New South Wales, 63, 226-272.

Davis, C. (1940a) Taxonomic notes of order Embioptera. Part XV: The genus Rhagadochir Enderlein, and genera convergent to it. Proceedings of the Linnean Society of New South Wales, 65, 171-191. 
Davis, C. (1940b) Taxonomic notes on the order Embioptera. Part XVII: A new neotropical genus previously confused with Embia Latreille. Proceedings of the Linnean Society of New South Wales, 65, 344-352.

Davis, C. (1940c) Taxonomic notes of order Embioptera. Part XX: The distribution and comparative morphology of the order Embioptera. Proceedings of the Linnean Society of New South Wales, 65, 533-542.

Davis, C. (1940d) Family classification of the order Embioptera. Annals of the Entomological Society of America, 33, 676-682.

Davis, C. (1942) Report on a collection of Embioptera from Trinidad and Guyana. Proceedings of the Royal Entomological Society of London B, 11, 111-119.

Enderlein, G. (1909) Die klassifikation der Embiidinen, nebst morphologichen und phisiologischen Bemerkungen, besonders über das Spinnen derselben. Zoolgischen Anzeiger, 35, 166-191.

Enderlein, G. (1912) Embiidinen. Collections Zoologiques du Baron Longchamps, Catalogue Systematique et Descriptif, Bruxelles, $\mathbf{3}$, $1-121$.

Farris, J.S., Albert, V.A., Källersjö, M., Lipscomb, D. \& Kluge, A.G. (1996) Parsimony jackknifing outperforms neighbor-joining. Cladistics, 12, 99-124.

Friederichs, K. (1934) Das Gemeinschaftsleben der Embiiden und Näheres zur Kenntnis der Arten. Archiv für Naturgeschichte, 3, 405-444.

Goloboff, P.A. (1993a) Estimating character weights during tree search. Cladistics, 9, 83-91.

Goloboff, P.A. (1993b) Pee-Wee: Parsimony and Implied Weights, version 2.7. San Miguel de Tucuman, Tucuman.

Goloboff, P.A., Farris, J.S., Källerjö, M., Oxelmann, B., Ramirez, M. \& Szumik, C.A. (2003) Improvements to resampling measures of group support. Cladistics, 19, 324-332.

Gray, G.R. (1832) The Animal Kingdom of Cuvier (ed. by E. Griffith and E. Pidgeon), pp. 346-347. Whittaker, London.

Horovitz, I. (1999) A report on 'One day symposium on numerical cladistics'. Cladistics, 15, 177-182.

Krauss, H.A. (1911) Monographie der Embien. Zoologica Stuttgart, 23, $1-78$.

Mariño, E. \& Márquez, C. (1988) Embiopteros de Mexico. IV. Descripcion de una nueva especie del genero Clothoda Enderlein, 1909. Anales del Instituto de Biologia de la Universidad Nacional Autonoma de Mexico, Serie Zoologica, 58, 63-68.

Navas, L. (1918) Embiopteros (Ins.) de America Meridional. Broteria, Serie Zoologica, 16, 85-110.

Nixon, K. (1999) The parsimony ratchet, a new method for rapid parsimony analysis. Cladistics, 14, 407-414.
Ross, E.S. (1944) A revision of the Embioptera or web-spinners, of the New World. Proceedings of the Entomological Society of Washington, 94, 401-504.

Ross, E.S. (1952) The Embioptera of Angola. Publicações Culturais da Companhia de Diamantes de Angola, 14, 41-54.

Ross, E.S. (1960) Parthenogenetic African Embioptera. Wasmann Journal of Biology, 18, 297-304.

Ross, E.S. (1970) Biosystematics of the Embioptera. Annual Review of Entomology, 5, 157-172.

Ross, E.S. (1971) A new neotropical genus and species of Embioptera. Wasmann Journal of Biology, 29, 29-36.

Ross, E.S. (1984) A classification of the Embiidina of Mexico with descriptions of new taxa. Occasional Papers of the California Academy of Sciences, 140, 1-56.

Ross, E.S. (2000) Origin, relationships and integumental anatomy of the insect order Embiidina. Embia, Part 1. Occasional Papers of the California Academy of Sciences, 149, 1-53.

Ross, E.S. (2001) The Embiidae of the Americas (order Embiidina). Embia, Part 3. Occasional Papers of the California Academy of Sciences, 150, 1-86.

Szumik, C.A. (1994) Oligembia vetusta, a new fossil Teratembiid (Embioptera) from Dominican amber. Journal of the New York Entomological Society, 102, 67-73.

Szumik, C.A. (1996) The higher classification of the order Embioptera: a cladistic analysis. Cladistics, 12, 41-64.

Szumik, C.A. (1998a) Embioptera. Biodiversidad de artropodos argentinos (ed. by S. Coscaron and J. J. Morrone), pp. 32-37. Ediciones del Sur, Argentina.

Szumik, C.A. (1998b) Two new Neotropical genera of Embiidae (Embioptera, Insecta). Journal of the New York Entomological Society, 105, 140-153.

Szumik, C.A. (2000a) The Embiopteran classification (Insecta). Presented at the XIX Hennig Meeting of the Willy Hennig Society, 28 May-2 June 2000, Leiden.

Szumik, C.A. (2000b) Phylogeny of Embioptera (Insecta) revisited. Presented at the XXI International Congress of Entomology/ XVIII Brazilian Congress of Entomology, 20-26 August 2000, Foz do Iguazú.

Szumik, C.A. (2002) Embioptera. Biodiversidad, taxonomia y biogeografia de artropodos de Mexico: hacia una sintesis de su conocimiento (ed. by J. Llorente Bousquets and J. J. Morrone), pp. 441-448. Universidad Nacional Autonoma de Mexico, Mexico.

Accepted 25 August 2003 


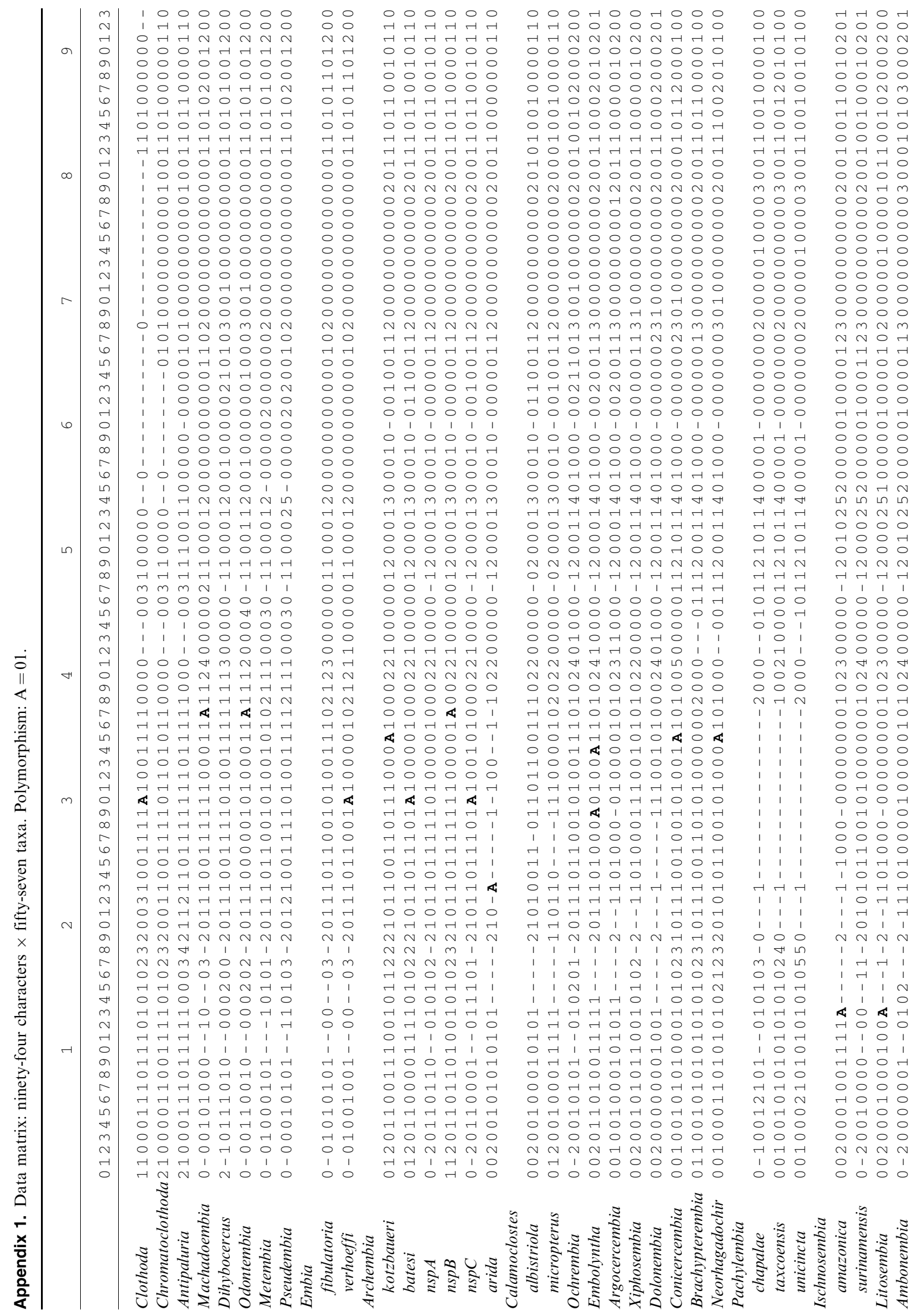




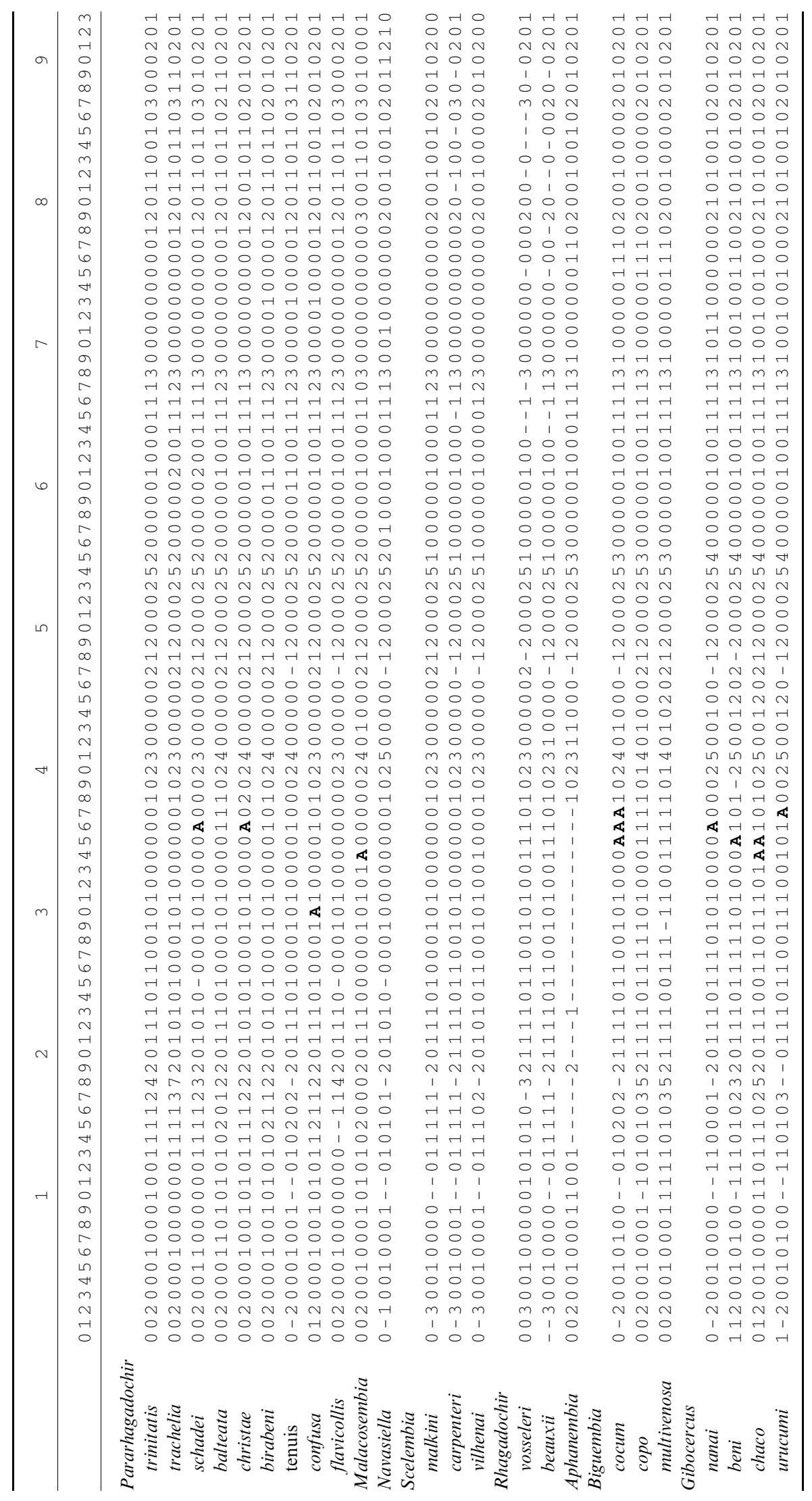




\section{Appendix 2}

List of species studied for the cladistic analysis.

Outgroup

Clothoda nobilis (Gerstaecker) BRAZIL: paratypes (USNM)

Antipaluria urichi (De Saussure) TRINIDAD: common material (CU, USNM, AMNH)

Antipaluria silvestris Ross VENEZUELA: paratypes (USNM)

Chromatoclothoda aurata Ross PERU: paratypes (USNM) Chromatoclothoda elegantula Ross BRAZIL: paratypes (USNM)

Odontembia spinosa (Navas) CONGO R.D.: holotype (MRAC)

Embia verhoeffi Friederichs MOZAMBIQUE: holotype (ZMB)

Embia fibulatoria Enderlein CAMEROON: paratypes (ZMB)

Machadoembia angolica Ross ANGOLA: paratypes (MCZ, USNM)

Machadoembia arcuata Ross CONGO R.D.: holotype (MRAC)

Dihybocercus basilewskyi Ross BURUNDI: holotype (MRAC)

Dihybocercus severini Enderlein CONGO R.D.: holotype (MRAC)

Pseudembia truncata Davis INDIA: holotype (MCZ)

Pseudembia ferox (Davis) INDIA: holotype (MCZ)

Pseudembia immsi (Davis) INDIA: holotype (MCZ)

Metembia flava Davis INDIA: holotype (MCZ)

Ingroup

Archembia kotzbaueri (Navas) BRAZIL: common material (MNRJ, MZSP, USNM lacombea paratypes)

Archembia batesi (MacLachlan) BRAZIL, PERU: common material (USNM, AMNH)

Biguembia cocum Szumik BRAZIL: holotype and paratypes (MZSP)

Biguembia copo Szumik ARGENTINA: holotype and paratypes (IFML)

Brachypterembia moreliensis Ross MEXICO: paratypes (USNM)

Conicerembia tepicensis Ross MEXICO: paratypes (USNM)

Gibocercus chaco Szumik ARGENTINA: holotype, common material (IFML)

Gibocercus urucumi Szumik BRAZIL: holotype (MZSP)

Gibocercus beni Szumik BOLIVIA: holotype and paratypes (MCZ)

Gibocercus nanai Szumik PERU: holotype (USNM)

Malacosembia tucumanensis Ross ARGENTINA: common material (IFML)
Neorhagadochir salvini (McLachlan) MEXICO, EL SALVADOR, HONDURAS: common material (IBUNAM, USNM, CMNH)

Ochrembia wagneri (Navas) ARGENTINA: holotype (MNHN), common material (IFML)

Pachylembia chapalae Ross MEXICO: paratypes (USNM) Pachylembia taxcoensis Ross MEXICO: paratypes (USNM)

Pachylembia unicincta Ross MEXICO: paratypes (USNM) Pararhagadochir trinitatis (De Saussure) TRINIDAD, COLOMBIA: common material (AMNH, CU, USNM, $\mathrm{MCZ})$

Pararhagadochir balteata Ross BRAZIL: paratypes (USNM), common material (MZSP)

Pararhagadochir birabeni (Navas) ARGENTINA: common material (MACN, IFML)

Pararhagadochir christae Ross BRAZIL: paratypes (USNM)

Pararhagadochir confusa Ross PARAGUAY, ARGENTINA: paratypes (MCZ), common material (IFML)

Pararhagadochir tenuis (Enderlein) BOLIVIA: holotype (HUBN), common material (IFML)

Pararhagadochir trachelia (Navas) ARGENTINA: common material (IFML, MACN)

Pararhagadochir flavicollis (Enderlein) BOLIVIA: common material (USNM, IFML)

Pararhagadochir schadei Ross PARAGUAY, ARGENTINA: paratypes (MCZ), common material (IFML)

Pararhagadochir surinamensis Ross SURINAM: holotype (CU)

Rhagadochir malkini Ross ANGOLA: paratype (MCZ)

Rhagadochir vilhenai Ross ANGOLA: paratype (MRAC)

Navasiella sulcata (Navas) CONGO R.D.: holotype $(\mathrm{MNHN})$

\section{Appendix 3}

List of characters used in the cladistic analysis.

Head

0. Interocular elliptical area not pigmented (males): (0) no; (1) yes; (2) yes, but in a prominent elevation (in some Clothodidae).

1. Interocular elliptical area not pigmented (females): (0) no; (1) yes; (2) yes, in a prominent elevation.

2. Number of molar teeth on left and right mandibles (males): (0) 2-1, teeth strong, as well defined as incisive teeth; (1) 2-1, teeth strong, but less defined than incisive teeth; (2) 2-1, same as (1) but one of the left molar teeth inconspicuous; (3) 1-1, just one molar tooth.

3. Mandibles: (0) depressed; (1) tubular.

4. Incisive teeth concentrated on tip of mandibles: (0) no; (1) yes.

5. Mm sclerotized: (0) no (Fig. 5); (1) yes (Figs 1-4). 
6. Anterior margin of Sm: (0) straight and well defined (Figs 2, 3); (1) concave (Fig. 5); (2) W-like (2 small concavities).

7. Sm, base: (0) narrow, same width as anterior margin (Figs 1, 5); (1) broad, wider than anterior margin (Figs 2-4).

8. Sm pilose: (0) no; (1) yes (Fig. 1).

9. Prothorax pigmented (male): (0) no; (1) yes.

10. Prothorax pigmented (female): (0) no; (1) yes.

11. Apical antennal segments pigmented (male): (0) yes; (1) no.

12. Apical antennal segments pigmented (female): (0) yes; (1) no.

\section{Hind basitarsus}

13. Middle bladder: (0) absent (Fig. 8); (1) present (Figs 6, 7, 9, 10).

14. Shape of middle bladder: (0) large (more than $50 \%$ of width of basitarsus; Figs 6, 7); (1) small (less than $40 \%$ of width of basitarsus; Figs 9, 10).

15. Position of middle bladder: (0) basal; (1) medial (Figs 6, 7); (2) apical (Fig. 10).

16. Shape of apical bladder: (0) large (Figs 6, 7); (1) small (Figs 8, 9).

17. Number of prolateral rows (male): (0) one; (1) 2; (2) 3; (3) 4 ; (4) 5 ; (5) 6.

18. Number of prolateral rows (female): (0) one; (1) 2; (2) 3 ; (3) 4 ; (4) 5 ; (5) 6 ; (6) 7; (7) 8 .

Wings

19. Wings: (0) absent; (1) reduced; (2) present.

20. Wing base union (Szumik, 1996): (0) 'type A', Rs + Ma and $\mathrm{Mp}$ start together from $\mathrm{Cu}$, and a broad cross-vein present between $\mathrm{Rs}+\mathrm{Ma}$ and $\mathrm{R}_{1}$ (Figs 14, 15); (1) 'type B', Rs + Ma and Mp start separately from $\mathrm{R}_{1}$ and $\mathrm{Cu}$ (Fig. 11); (2) 'type C', Rs + Ma and Mp start fused from $\mathrm{R}_{1}$ and $\mathrm{Cu}$.

21. Anal region: (0) large (Fig. 11); (1) small (Figs 12-15).

22. Cu forked: (0) no; (1) yes, with 2 veins (Figs 11-15); (2) yes, with 3 veins; (3) yes, with 4 veins.

23. Ma forked: (0) no; (1) yes (Figs 11-15).

24. Anal forked: (0) no; (1) yes (Fig. 11).

25. Cua: (0) conspicuous; (1) diffuse.

26. Mal finished on the wing edge: (0) no (Figs 14, 15); (1) yes (Figs 12, 13).

27. Ma2 finished on the wing edge: (0) no (Figs 14, 15); (1) yes (Fig. 12).

28. Mp finished on the wing edge: (0) no (Figs 11-15); (1) yes.

29. Cross-veins present between $C$ and $R_{1}$ : (0) no; (1) yes (Figs 11-15).

30. Cross-veins present between $R s$ and Ma: (0) no (Figs 12-15); (1) yes (Fig. 11).
31. Cross-veins present between Rs and Ma1: (0) no; (1) yes (Figs 11-15).

32. Cross-veins present between $R_{l}$ and $R s+M a$ : (0) no; (1) yes.

33. Cross-veins present between $R s+M a$ and $M p$ : (0) no; (1) yes.

34. Cross-veins present between $M a 2$ and $M p:$ (0) no (Figs 11, 13-15); (1) yes (Fig. 12).

35. Cross-veins present between Mal and Ma2: (0) no (Figs 11, 13-15); (1) yes (Fig. 12).

36. Cross-veins present between Ma and Mp: (0) no (Figs 12, 15); (1) yes (Figs 11, 13, 14).

37. Cross-veins present between $\mathrm{Mp}$ and Cua: (0) no (Figs 11, 13-15); (1) yes (Fig. 12).

\section{Terminalia}

38. Longitudinal ratio between basal and apical cerci: (0) apical cerci longer than basal; (1) both the same length; (2) apical cerci shorter; (3) apical cerci very short, less than half length of basal cerci.

39. Internal face of LC1 depressed: (0) no; (1) yes.

40. LC1, setae distribution: (0) absent; (1) present, on apical and medial area; (2) present, on apical area.

41. LC1dp, shape: (0) absent (Fig. 36); (1) dome-shaped process; (2) conical process, where caudal and anterior margins are oblique to longitudinal axis of LC1 (Fig. 37); (3) semiglobose process, caudal margin oblique and anterior margin perpendicular to longitudinal axis of $\mathrm{LC1}$; (4) square process, caudal and anterior margins perpendicular to longitudinal axis of LC1 (Fig. 42); (5) tubular, same as (4) but process is longer than width of LC1 (Fig. 41).

42. LC1dp, position: (0) apical (Figs 38, 40-42); (1) medial (Figs 37, 39).

43. LC1dp, depressed: (0) no; (1) yes.

44. Semiglobose convexity on dorsal face of LCIdp: (0) no; (1) yes (Figs 40, 41).

45. LC1, basal node: (0) absent; (1) present, internal and without setae; (2) present, internal with setae (Fig. 41); (3) present, dorsal with setae; (4) present, ventral with setae.

46. LC1, base: (0) narrow (LC1 tubular); (1) broad (LC1 conical, Fig. 36), this condition is only present in Neorhagadochir (= Brachypterembia).

47. $1^{\circ} V f_{S}$ (female): (0) well developed, well separated from central plate (Fig. 18); (1) well developed, partially separated from central plate (Fig. 17); (2) differentiated from central plate by 2 notches on caudal margin (Fig. 16); (3) inconspicuous, differentiated from central plate by degree of pigmentation.

48. 9T: (0) with a discoidal area sclerotized on middle of tergite, only present in Calamoclostes; (1) uniformly sclerotized.

49. 10T shape: (0) one plate; (1) 2 subequal plates; (2) 2 different plates.

50. 10 T pilose: (0) no; (1) yes. 
51. 10L diagonally elevated: (0) no; (1) yes.

52. 10Lp1 start in inner anterior angle: (0) no; (1) yes.

53. Tip of 10Lp1: (0) absent; (1) simple (Figs 19-22); (2) forked (Figs 23-27).

54. 10Lp1 shape: (0) absent; (1) small lobe; (2) sharp hook; (3) straight and flat stick (Figs 19, 20); (4) curved and flat stick (Fig. 21); (5) stick with an internal hook and external laminate lobe (Figs 23-27).

55. 10Lpl forked: (1) internal tip (hook) and external tip (flat lobe) fused (present in Rhagadochir (= Scelembia)); (2) same as (1), tips separated (e.g. Pararhagadochir, Figs 23-25); (3) internal and external tips longer and conical (Biguembia, Fig. 26); (4): same as (3) but internal tip broad (Gibocercus, Fig. 27).

56. Internal face of 10Lp laminate: (0) no; (1) yes.

57. Laminate carina on 10Lp 1: (0) no; (1) yes.

58. 10Lp with apex expanded: (0) no; (1) yes.

59. 10Lpl reduced to a small hook: (0) no; (1) yes, only present in Pachylembia.

60. Shape of external tip of 10Lp1: (0) lobed; (1) bilobed (Fig. 23). Exclusive of some species of Pararhagadochir.

61. 10Lp1 base: (0) absent; (1) shorter; (2) longer.

62. External margin of 10Lp1: (0) regular; (1) irregular.

63. Longitudinal carinae on 10Lp1: (0) absent; (1) one (Fig. 19); (2) many.

64. Depression between 10Lp and 10L: (0) absent; (1) present; (2) same as (1) but more depressed.

65. Internal anterior angle of $10 L$ excavated: (0) no; (1) yes.

66. Caudal margin of 10L: (0) convex; (1) concave.

67. Basal area of 10R membranous: (0) no; (1) yes, but only a smaller area; (2) yes, but a larger area (half the plate).

68. Caudal process of $10 R$ (10Rp1): (0) absent; (1) a small and rounded lobe; (2) a small and sharp tip; (3) a forked process (Figs 29, 30), with a dorsal tip (hooklike, well sclerotized) and a ventral tip (unsclerotized lobe).

69. 10Rp1, dorsal tip well developed: (0) no; (1) yes (Figs 31, 32).
70. 10Rp1, ventral tip well developed: (0) no; (1) yes.

71. 10Rp1, ventral tip sclerotized: (0) no; (1) yes.

72. 10Rp1 strongly depressed on external margin: (0) no; (1) yes.

73. Base of 10Rp1 prolonged, longer than length of 10R: (0) no; (1) yes.

74. Apex of 10Rpl truncated: (0) no, (1) yes (Fig. 28).

75. Microtrichiae in 10Rp1: (0) no; (1) yes (Fig. 31).

76. 10Rp1 with a longitudinal keel: (0) no; (1) yes.

77. Convexity on base of 10Rp1: (0) no; (1) yes (Fig. 31).

78. Anterior process of $10 R$ (10Rp2) with longitudinal laminate keels: (0) no; (1) yes.

79. 10Rp2, shape: (0) lateral flap extended over 10Lp1, parallel to 10R; (1) incipient lobe; (2) rodlike, longer, oblique to 10R; (3) same as (2) but diffuse.

80. 10Rp2, broad and discoidal: (0) no; (1) yes.

81. Microtrichiae in 10Rp2: (0) no; (1) yes.

82. Hp with transversal keels: (0) no; (1) yes (Figs 33-35).

83. Hp centred, lobed, with unsclerotized margins: (0) yes (Figs 34, 35); (1) no (Fig. 33).

84. Node with microtrichiae between LC1 and 10L: (0) no; (1) yes.

85. Lpp fused to $H$ : (0) no; (1) yes.

86. Lpp partially membranous: (0) no (Figs 34, 35); (1) yes (Fig. 33).

87. Internal caudal angle of Lpp: (0) without a process; (1) with a thornlike process; (2) with a prominent node (Fig. 34); (3) with a flat hook (Fig. 35).

88. Node on external anterior angle of Lpp: (0) no; (1) yes.

89. Microtrichiae in Lpp: (0) no; (1) yes.

90. Rpp: (0) reduced; (1) well developed.

91. Shape of Ep: (0) inconspicuous; (1) broad sclerotized plate; (2) narrow sclerotized band.

92. Ep-10Rp2 fused: (0) no; (1) yes, condition present in Anisembiidae, in some species of Clothodidae, and in Archembia and Calamoclostes.

93. Ep elevated caudally: (0) no; (1) yes. 
Appendix 4. Character number, fit, steps and extra steps for the optimal trees.

\begin{tabular}{|c|c|c|c|c|c|c|c|}
\hline Character & Fit & Steps & Extra steps & Character & Fit & Steps & Extra steps \\
\hline 0 & 3.7 & 7 & 5 & 47 & 5.0 & 6 & 3 \\
\hline 1 & 3.7 & 6 & 5 & 48 & 10.0 & 1 & 0 \\
\hline 2 & 5.0 & 6 & 3 & 49 & 10.0 & 2 & 0 \\
\hline 3 & 6.0 & 3 & 2 & 50 & 7.5 & 2 & 1 \\
\hline 4 & 7.5 & 2 & 1 & 51 & 10.0 & 1 & 0 \\
\hline 5 & 2.5 & 10 & 9 & 52 & 7.5 & 2 & 1 \\
\hline 6 & 2.7 & 10 & 8 & 53 & 7.5 & 3 & 1 \\
\hline 7 & 2.5 & 10 & 9 & 54 & 5.0 & 7 & 3 \\
\hline 8 & 10.0 & 1 & 0 & 55 & 10.0 & 4 & 0 \\
\hline 9 & 1.7 & 15 & 14 & 56 & 7.5 & 2 & 1 \\
\hline 10 & 3.0 & 8 & 7 & 57 & 6.0 & 3 & 2 \\
\hline 11 & 2.3 & 11 & 10 & 58 & 10.0 & 1 & 0 \\
\hline 12 & 3.3 & 7 & 6 & 59 & 10.0 & 1 & 0 \\
\hline 13 & 6.0 & 3 & 2 & 60 & 10.0 & 1 & 0 \\
\hline 14 & 3.0 & 8 & 7 & 61 & 6.0 & 4 & 2 \\
\hline 15 & 2.7 & 10 & 8 & 62 & 7.5 & 2 & 1 \\
\hline 16 & 3.0 & 8 & 7 & 63 & 2.7 & 10 & 8 \\
\hline 17 & 1.4 & 23 & 18 & 64 & 3.7 & 6 & 5 \\
\hline 18 & 2.1 & 18 & 11 & 65 & 4.2 & 5 & 4 \\
\hline 19 & 6.0 & 4 & 2 & 66 & 6.0 & 3 & 2 \\
\hline 20 & 5.0 & 4 & 3 & 67 & 2.0 & 14 & 12 \\
\hline 21 & 7.5 & 2 & 1 & 68 & 4.2 & 7 & 4 \\
\hline 22 & 2.7 & 11 & 8 & 69 & 6.0 & 3 & 2 \\
\hline 23 & 7.5 & 2 & 1 & 70 & 7.5 & 2 & 1 \\
\hline 24 & - & - & - & 71 & 4.2 & 5 & 4 \\
\hline 25 & 2.7 & 9 & 8 & 72 & 10.0 & 1 & 0 \\
\hline 26 & 3.7 & 6 & 5 & 73 & 10.0 & 1 & 0 \\
\hline 27 & 3.0 & 8 & 7 & 74 & 7.5 & 2 & 1 \\
\hline 28 & 3.3 & 7 & 6 & 75 & 7.5 & 2 & 1 \\
\hline 29 & - & - & - & 76 & 7.5 & 2 & 1 \\
\hline 30 & 2.5 & 10 & 9 & 77 & 10.0 & 1 & 0 \\
\hline 31 & 6.0 & 3 & 2 & 78 & 7.5 & 2 & 1 \\
\hline 32 & 6.0 & 3 & 2 & 79 & 5.0 & 6 & 3 \\
\hline 33 & 6.0 & 3 & 2 & 80 & 10.0 & 1 & 0 \\
\hline 34 & 2.3 & 11 & 10 & 81 & 3.3 & 7 & 6 \\
\hline 35 & 3.0 & 8 & 7 & 82 & 6.0 & 3 & 2 \\
\hline 36 & 3.7 & 6 & 5 & 83 & 5.0 & 4 & 3 \\
\hline 37 & 3.7 & 6 & 5 & 84 & 6.0 & 3 & 2 \\
\hline 38 & 1.8 & 15 & 13 & 85 & 3.0 & 8 & 7 \\
\hline 39 & 10.0 & 1 & 0 & 86 & 4.2 & 5 & 4 \\
\hline 40 & 4.2 & 6 & 4 & 87 & 1.2 & 24 & 21 \\
\hline 41 & 1.2 & 27 & 22 & 88 & 5.0 & 4 & 3 \\
\hline 42 & 3.7 & 6 & 5 & 89 & 2.3 & 11 & 10 \\
\hline 43 & 5.0 & 4 & 3 & 90 & 7.5 & 2 & 1 \\
\hline 44 & 10.0 & 1 & 0 & 91 & 4.5 & 6 & 4 \\
\hline 45 & 3.7 & 9 & 5 & 92 & 6.0 & 3 & 2 \\
\hline 46 & 10.0 & 1 & 0 & 93 & 5.0 & 4 & 3 \\
\hline
\end{tabular}

